\title{
Tandem, long-duration, ultra-high-altitude tethered balloon and its system characteristics
}

\author{
Donghui Zhang ${ }^{\mathrm{a}, \mathrm{b}, *}$, Haibo Luo ${ }^{\mathrm{a}}$, Yanxiang Cui ${ }^{\mathrm{a}}$, Xiaohui Zeng ${ }^{\mathrm{c}}$, Sheng Wang ${ }^{\mathrm{a}, \mathrm{b}}$ \\ a Aerospace Information Research Institute, Chinese Academy of Sciences, Beijing 100094, China \\ ${ }^{\mathrm{b}}$ University of Chinese Academy of Sciences, Beijing 100190, China \\ ${ }^{\mathrm{c}}$ Institute of Mechanics, Chinese Academy of Sciences, Beijing 100090, China
}

Received 21 April 2020; received in revised form 28 July 2020; accepted 3 August 2020

Available online 18 August 2020

\begin{abstract}
In this paper, we propose a tandem tethered balloon scheme as a solution for increasing the operating altitudes of balloons to nearspace altitudes of more than $20 \mathrm{~km}$. By adding a middle balloon with a smaller volume than that of the top balloon in the middle weak wind zone, this scheme partially offsets the weight of the tether above the middle balloon, thereby greatly increasing the operating altitude of the tethered balloon. Another significant advantage of this scheme is that, when the working altitude exceeds $20 \mathrm{~km}$, the opposite directions of the winds at high and low altitudes can be exploited to reduce the horizontal displacement of the top balloon, raising the safety factor and the wind-resistant capabilities of the tether. In this paper, a three-dimensional static model is established for the tandem ultra-high-altitude tethered balloon, and a static equilibrium governing equation of the tandem ultra-high-altitude tethered balloon is derived. In addition, a design method based on the principle of the tether safety factor has been proposed for the tandem tethered balloon. For the first time, a sensitivity analysis was conducted for the tether resistance coefficient, balloon resistance coefficient, and balloon lift coefficient for the design optimization and flight test stages. Finally, we analyzed the three-dimensional cross-sectional profile of the tether, the maximum tension of the tether, the length of the tether, and the variation of the angle between the ground end of the tether and the horizontal plane for a tandem tethered balloon system that remained airborne continuously for one month. This work confirms that the model is viable in complex and variable wind field environments and capable of long-duration flights.
\end{abstract}

(C) 2020 COSPAR. Published by Elsevier Ltd. All rights reserved.

Keywords: Tethered balloon; Ultra-high altitude; Static model; Design method; Sensitivity analysis

\section{Introduction}

Near space has a wide range of application prospects for communication services, ground monitoring, aerial early warnings, and scientific research (Doliveira et al., 2016; Gonzalo et al., 2018). The United States, Japan, China, South Korea, and other countries have conducted investigations on prolonged airborne flight platforms for nearspace development, including the launch of near-space air-

\footnotetext{
* Corresponding author at: Aerospace Information Research Institute, Chinese Academy of Sciences, Beijing 100094, China.

E-mail address: zhangdh@aircas.ac.cn (D. Zhang).
}

ships (Bents, 2011; Xu et al., 2020), solar drones (Hwang et al., 2016; Zhu et al., 2014), long-duration superpressure balloons (Cathey, 2008; Saito et al., 2014; Yoder et al., 2019), and ultra-high altitude tethered balloons (Izetunsalan and Unsalan, 2011; Chiba et al., 2015).

Traditionally tethered balloons as long-duration aerial platforms have been widely used for military early warning and atmospheric surveillance systems as well as groundbased observations. The representative altitudes achieved by traditional tethered balloons are those of the $71 \mathrm{M}$ balloon of TCOM in the United States (Fig. 1) and the Jimu-1 balloon of the Chinese Academy of Sciences (CAS) 


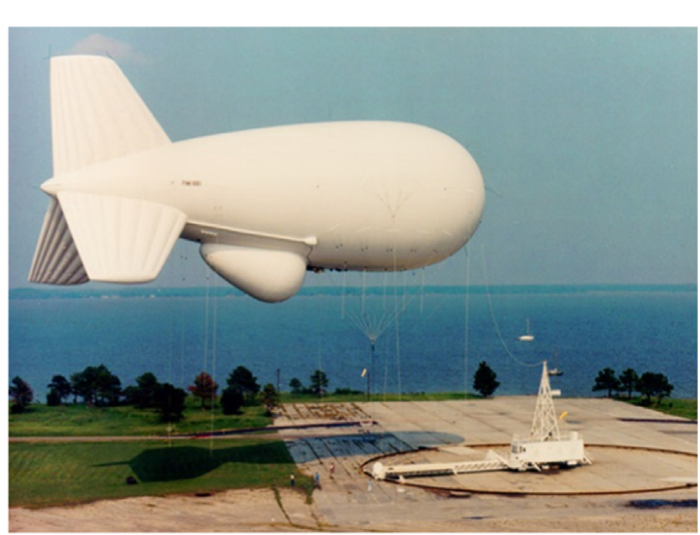

Fig. 1. TCOM 71M tethered balloon in the United States.

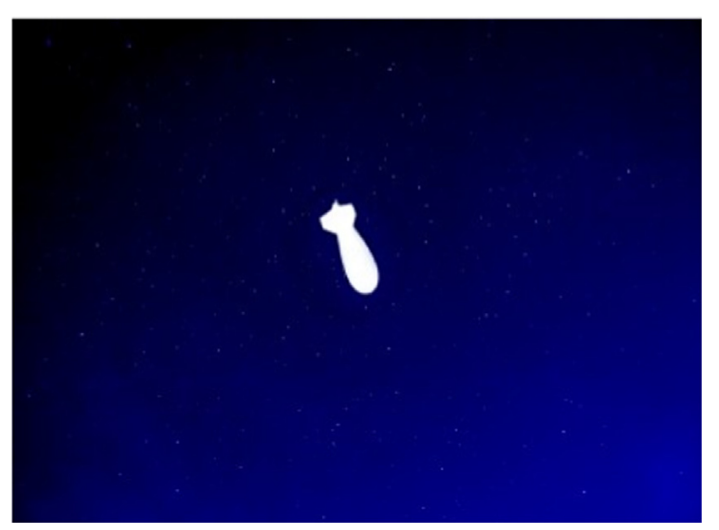

Fig. 2. Jimu-1 tethered balloon of the Chinese Academy of Sciences.

(Fig. 2). The $71 \mathrm{M}$ balloon can carry a payload of $1800 \mathrm{~kg}$ to an altitude of $4600 \mathrm{~m}$ and conduct continuous observations for up to $30 \mathrm{~d}$ (Jones and Schroder, 2001). The Jimu-1 tethered balloon of the Chinese Academy of Sciences (CAS) set a record in May 2019 for rising to an altitude of $7003 \mathrm{~m}$, and the CAS is currently conducting research on the 9000-m-altitude Jimu-2 balloon. The concept of an ultra-high-altitude tethered balloon was proposed by the Advanced Research Projects Agency of the United States (Menke, 1967). The balloon floats in the stratosphere and is moored on the ground by a tether. Compared to airships and UAVs, ultra-high-altitude tethered balloons use very little energy and have the intrinsic advantages of having fixed locations and long-duration flight capabilities. They have provided a new avenue for developing the stratosphere.

In addition to conventional applications, such as relays, atmospheric observations, and radar early warnings, which use ultra-high-altitude tethered balloons, the Jet Propulsion Laboratory in the United States proposed that longduration tethered balloons in the stratosphere at $22 \mathrm{~km}$ be used for small rocket launching to effectively reduce the fuel cost for the launch (Wilcox et al., 2011). Davidson et al. (Davidson et al., 2012) proposed the use of an ultrahigh-altitude tethered balloon to inject particles into the upper atmosphere to mitigate the problem of global warm- ing. Davidson also compared this method with other methods of transporting materials to the stratosphere and suggested that this method has cost and time advantages. At the 2013 symposium "Airships: A New Horizon for Science" hosted by the California Institute of Technology, stratospheric tethered balloons were discussed as a separate topic. This conference was centered around the idea that tethered stratospheric balloons have broad application prospects and research value (Miller et al., 2014).

TCOM analyzed the feasibility and parameter sensitivity of ultra-high-altitude tethered balloons in the 1990s (Euler et al., 1995; Badesha et al., 1996). Grant (Grant et al., 1996) used the Newton-Raphson iterative method to solve the two-dimensional dynamics equations of an established high-altitude tethered balloon and analyzed the static and dynamic lift-off processes of the system. Badesha and Bunn (2002) established a two-dimensional dynamic simulation model for stratospheric tethered balloons and a twodimensional wind field model, and they analyzed the responses of the balloon and tether under horizontal and vertical two-way airflow disturbances caused by a thunderstorm. Akita (2012) proposed a sea-anchored stratospheric tethered balloon that was easy to lift and recover and studied its feasibility.

Unlike conventional aerial vehicles, the performance of an ultra-high-altitude tethered balloon cannot be assessed using a single wind speed indicator, as it will be affected by the entire vertical profile of the wind field simultaneously. Based on the target operating locations and times of ultra-high altitude tethered balloons, none of the references above specified the vertical profile of the wind field at the location of the balloon and tether in advance, and the maximum wind speeds in the strong wind zone of the above studies were no greater than $31 \mathrm{~m} / \mathrm{s}$. In the second part of this paper, we analyze the wind field in July at the Siziwangqi Scientific Balloon Station in Inner Mongolia. July is the month with the lowest wind speed. The analysis shows that the wind speed in the strong wind zone reached $55 \mathrm{~m} / \mathrm{s}$. This poses a great challenge to the implementation of ultra-high-altitude tethered balloons, because as the wind speed increases, the horizontal offset distance of the balloon increases, the length of the tether increases, and the balloon will bear a greater weight. Eventually, the buoyancy of the balloon will not be sufficient to bear the weight of the tether, and simply increasing the balloon buoyancy will cause a direct increase in the tension in the tether and reduce the tether safety factor. This will be analyzed in detail in the third section of this paper. In the ultrahigh-altitude tethered balloon study of Chiba et al. (2017), the maximum wind speed in the strong wind zone reached nearly $50 \mathrm{~m} / \mathrm{s}$, but the diameter of the tether reached $50 \mathrm{~mm}$, and the weight of the tether alone exceeded $60 \mathrm{t}$. At present, the maximum balloon payload of NASA scientific balloons is only $6.35 \mathrm{t}$ (Kubara, 1974). Thus, this scheme has far exceeded the current technology level. Costello et al. (2012) proposed the use of tethers with streamlined cross-sectional shapes to reduce the drag force 
on the tether, thereby reducing the horizontal displacement of the balloon. However, the manufacturing difficulty of streamlined tethers and how to keep the streamlined shape of the tether aligned with the wind direction at all altitudes are the main problems to overcome.

During the winter-summer seasonal alternation, there are latitudinal wind transition layers and weak wind speed zones in the stratosphere (Belmont et al., 1975). By adding a middle balloon that is small in comparison with the top balloon in the middle weak wind zone, we can partially offset the weight of the tether above the middle balloon and thereby substantially increase the operating altitude of the tethered balloon. The analysis presented in this article showed that, while the tandem tethered balloon can increase the flight altitude, it can also take advantage of the wind field characteristic that the wind directions at high and low altitudes are opposite during the winter-summer seasonal alternation, which reduces the horizontal displacement of the balloon and the tether. The tether safety factor did not decrease but actually improved.

In this paper, we propose the scheme of a tandem, longduration, ultra-high-altitude tethered balloon and systematically analyze the advantages, parameter sensitivity, and flight stability of the tandem tethered balloon starting from static modeling analysis and design method research. The paper is organized as follows. In Section 2, we analyze the wind field and present the structural components of the ultra-high-altitude tethered balloon. In Section 3, a three-dimensional static model is established for the ultra-high-altitude tethered balloon. The static equilibrium equation is derived, and a comparison is made between the tandem tethered balloon and the single balloon in terms of the improvements to the safety factor of the tether and the wind-resistant capabilities. In Section 4, the design flow of the tandem tethered balloon is presented. A systematic analysis of the sensitivity to the tether diameter, the aerodynamic resistance coefficient of the tether, the aerodynamic resistance coefficient of the balloon, the aerodynamic lift coefficient, and the variation of the longduration flight parameters of the tandem tethered balloon are presented in Section 5. The final part of the paper provides conclusions.

\section{Tandem tethered balloon system in stratosphere}

In studies of single-balloon ultra-high-altitude tethered balloons (Euler et al., 1995; Badesha et al., 1996; Grant and Rand, 1996; Akita, 2012; Chiba et al., 2017), the target operating altitudes of the balloons were in the 20 - to $25-\mathrm{km}$ range. Through analysis presented in Section 3, we found that for a single-balloon scheme, as the operating altitude increases, the safety factor of the tether decreases. Furthermore, at high wind speeds, the problem of insufficient buoyancy will occur. By adding a balloon in the middle weak wind zone with a volume that is small compared to that of the top balloon, we partially offset the weight of the tether above the tandem balloon. We can thereby sub- stantially increase the operating altitude of the tethered balloon. Moreover, with the tandem scheme, the safety factor of the tether increased. This was because as the operating altitude increased from 20 to $30 \mathrm{~km}$, the wind field characteristic that the wind directions are opposite for the higher and lower altitude winds can be better used to strengthen the balloon's reverse drag force, offset the cumulative drag force of the tether in the strong wind zone, and reduce the horizontal displacement of the balloon, thereby achieving the goal of improving the safety factor and wind-resistant capabilities of the tether.

A prerequisite for studying the ultra-high-altitude tethered balloon is an understanding of the vertical profile of the wind field. Thus, we first analyze the wind field and then present the structural model of the tandem ultrahigh-altitude tethered balloon.

\subsection{Wind field environment}

At different latitudes, the stratospheric zonal wind transition layer and the weak wind zone occur at different times and altitudes and have different durations. In this work, we specifically analyzed the wind field data of the Siziwangqi Scientific Balloon station in Inner Mongolia (E111.9, N41.78) for the month of July in 2019. The wind field reversal in the $\mathrm{N} 41.78^{\circ}$ region actually lasts from the end of May to early September. The month of July was chosen for analysis because the wind speed in July was slightly smaller, and the wind direction at an altitude of $30 \mathrm{~km}$ was also more stable. The risks of conducting tests in other months will be higher. A stratospheric platform at an altitude of $30 \mathrm{~km}$ with a dwell time of one month has practical importance for many applications, such as detection of space particles and electromagnetic fields and for biological space exposure experiments. The source of the data was the European Centre for Medium-Range Weather Forecasts (ECMWF), and the analyzed data are valid for regions at the same latitude.

The wind velocity data in July were plotted as wind speed and direction diagrams, as shown in Fig. 3. The vertical profiles of the wind field at four times during a day in July are shown, for a total of 124 wind speed and direction curves. Each colored curve represents the vertical profile of the wind speed or direction at a specific time. The wind speed map shows that, from 8 to $15 \mathrm{~km}$, there was a strong wind zone with wind speeds exceeding $30 \mathrm{~m} / \mathrm{s}$ for long durations and reaching a maximum speed of $55 \mathrm{~m} / \mathrm{s}$. From 18 to $20 \mathrm{~km}$, there was a clear weak wind zone with wind speeds of generally less than $10 \mathrm{~m} / \mathrm{s}$. Above $20 \mathrm{~km}$, the wind speed increased slowly. In the wind direction diagram, $0^{\circ}$ represents a north wind direction, and $90^{\circ}$ direction represents an east wind direction. The wind direction diagram shows that there was a clear wind direction change at $19-20 \mathrm{~km}$. Below this altitude, the wind was predominately a west wind, and the wind direction gradually transitioned to a stable east wind above $20 \mathrm{~km}$. It is precisely this characteristic that allows a balloon to be positioned 

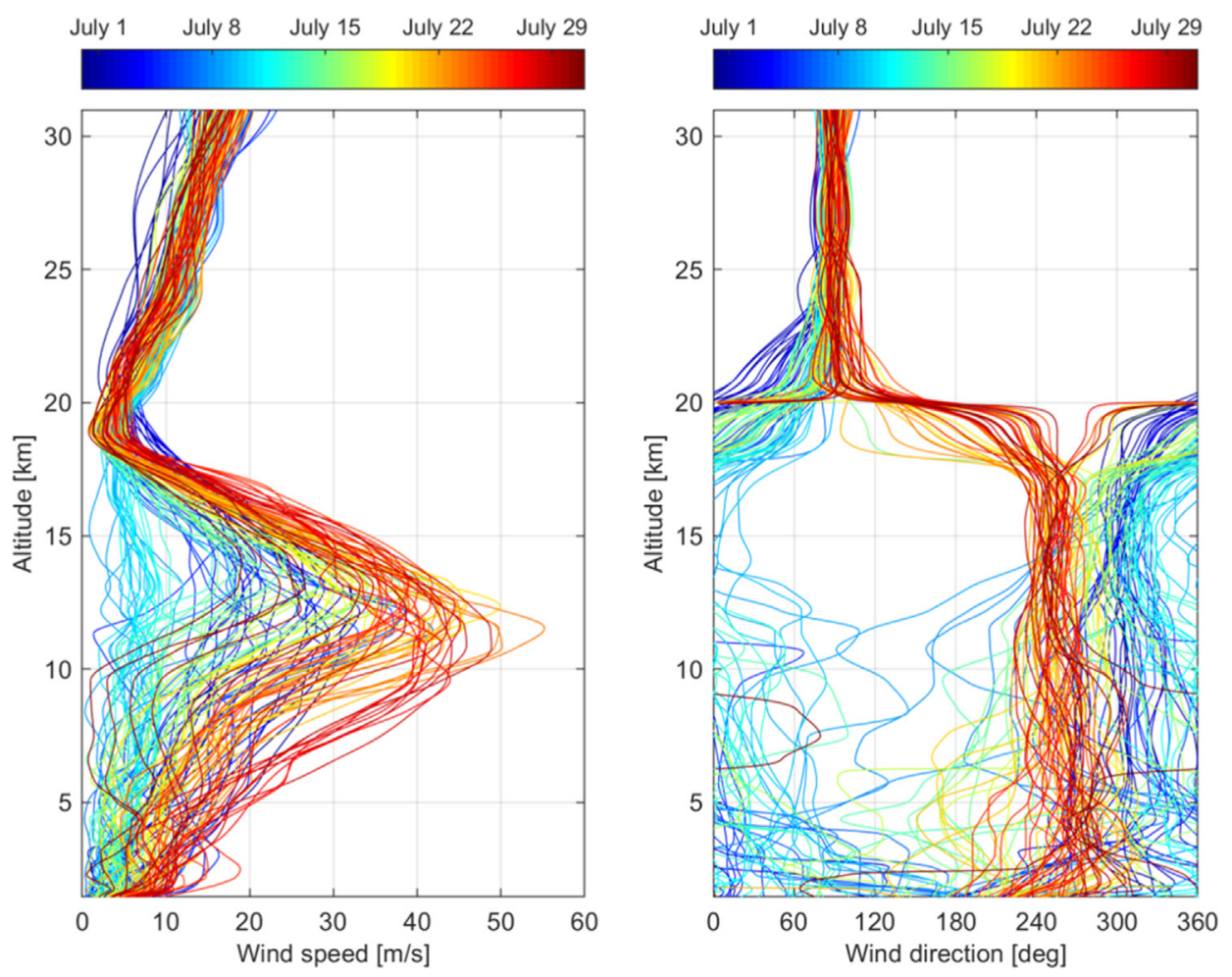

Fig. 3. Wind speed and direction curves.

in the upper eastward wind zone to partially or fully offset the drag force on the tether in the strong west wind zone.

For convenience during the subsequent simulation analysis, we performed a statistical probability analysis of the wind field data shown in Fig. 3 using the Kaplan-Meier estimate method and obtained the probability distribution of the wind field data shown in Fig. 4. The wind direction curve represents the average of 124 wind direction data points at each altitude in a month. The wind speed data provided the $70 \%, 80 \%, 90 \%$, and maximum wind speed curves based on the empirical cumulative distribution, and the maximum wind speed curve shows the maximum wind speed at each altitude.

\subsection{Platform configuration}

Honeywell, Vitro Corporation, and Goodyear Aerospace Corporation proposed three tandem-style tethered balloon structures for applications at an operating altitude of $30 \mathrm{~km}$ and a payload-carrying capacity of $500 \mathrm{lb}$ (Menke, 1967). In all three schemes, one or more balloons are installed at an altitude below $15 \mathrm{~km}$ to offset the weight of the tether. However, due to the presence of the strong wind zone at an altitude of $6-15 \mathrm{~km}$, there is a high aerodynamic pressure, so all three schemes use streamlined balloons composed of composite material. The streamlined composite balloons are heavy and complicated to manufacture. To provide the same net buoyancy, the balloons must have a greater volume. This ultimately leads to a large, complex, and costly system that cannot be applied in prac-

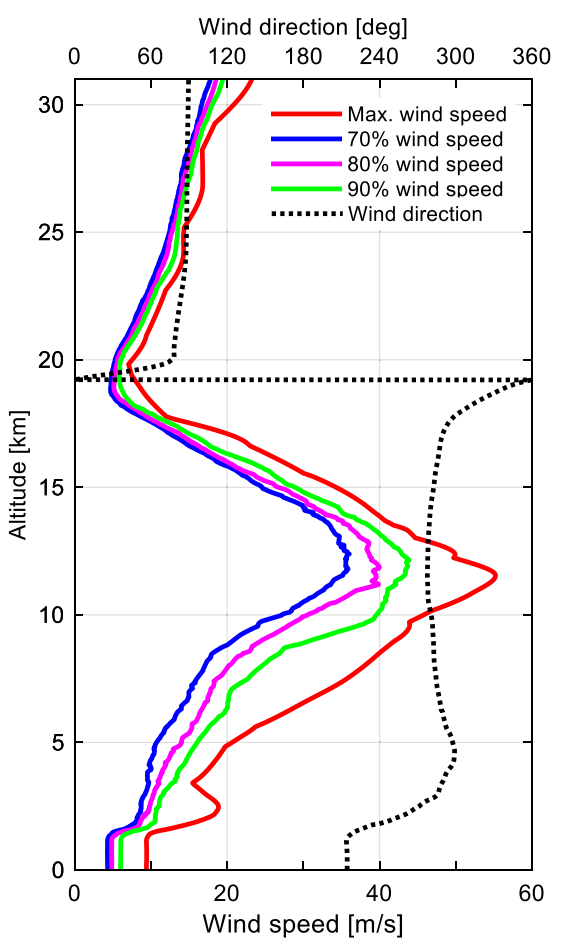

Fig. 4. Wind field probability distribution statistics.

tice. The tandem-style tethered balloon scheme proposed herein is different from the above schemes. We positioned the middle balloon in the low-wind-speed zone at $20 \mathrm{~km}$, where the lower air density and low wind speed reduced the aerodynamic pressure on the balloon. Thus, the middle 
balloon can be constructed from a low-cost polyethylene film. It only requires the use of a small-volume middle balloon to partially offset the weight of the tether, which can dramatically reduce the system complexity and construction cost. A preliminary estimate shows that the cost of a balloon made of a polyethylene film is one to two orders of magnitude lower than the cost of a composite balloon. In addition, the maximum volume of a streamlined tethered balloon is $16,800 \mathrm{~m}^{3}$ (used in the United States), whereas a super-pressure balloon made of polyethylene film can reach a volume greater than $500,000 \mathrm{~m}^{3}$. Superpressure balloons made of polyethylene films are more amenable to future upgrades of the system capabilities.

In the proposed scheme, the top balloon operates at $30 \mathrm{~km}$, where the wind speed is distributed between 10 and $20 \mathrm{~m} / \mathrm{s}$, and the middle balloon operates near $20 \mathrm{~km}$, where the wind speed is distributed between 5 and $10 \mathrm{~m} /$ s. The two balloons are located at altitudes where the atmospheric density is low and the wind speed is much smaller than that in the strong wind zone. Although the aerodynamic pressures on the balloons are small, the balloons require streamlined shapes or construction with composite materials. According to Eq. (5) (discussed below), the dynamic pressure generated by the wind on the top balloon is $0.9-3.6 \mathrm{~Pa}$, and the dynamic pressure generated by the wind on the middle balloon is 1.1-4.4 Pa. Given that the internal pressure of a $532,200 \mathrm{~m}^{3}$ super-pressure balloon that NASA routinely flies may reach $180 \mathrm{~Pa}$ (Cathey et al., 2017), the aerodynamic pressure here would not affect the overall shape of the balloon.

Fig. 3 shows that the direction of the wind field at the altitude of the top balloon is a stable east wind, and the balloon can generate a stable westward aerodynamic resistance, which is used to offset or partially offset the eastward aerodynamic resistance generated by the tether in the strong wind zone and to achieve the goal of reducing the horizontal displacement of the tether and its weight. The middle balloon operates near the altitude of $20 \mathrm{~km}$ and is used to supplement the balloon buoyancy, which is counteracted by the weight of the tether between 20 and $30 \mathrm{~km}$. This increases the tether tension in the vertical direction, further reduces the horizontal displacement of the tether, and improves the system's wind-resistant capabilities.

The tandem balloon structure proposed in this paper is shown in Fig. 5. A gondola is suspended at the lower end of the top balloon. The main operating payload is installed in the gondola. Solar cells are installed around the gondola to provide renewable energy for the equipment in the gondola. The middle balloon is connected to the middle of the tether. The balloon is designed to have a connecting cable inside that is fixed to the lower end of the balloon and has an air-tight sliding connection at the top of the balloon. The buoyant force of the balloon is transmitted to the connecting cable through the lower connection point. The tension in the tether is transmitted through the connecting cable in the middle of the middle balloon without affecting the films of the balloon, and therefore, the balloon maintains its original shape. The lower end of the tether is connected to the ground winch, and the length of the tether is controlled by the winch in real-time to adjust the operating altitude of the top balloon. For example, as the wind speed increases, the tether drift distance increases. The balloon may be maintained at the required height by winding up the tether with the winch on the ground. When the internal temperature of the balloon rises too much and causes excessive internal pressure in the balloon, the tether may be retracted with the ground winch to lower the balloon height and reduce the internal pressure.

The tether length of an ultra-high-altitude tethered balloon is several to tens of times that of a conventional tethered balloon. As it passes the strong wind zone with wind speed of $50 \mathrm{~m} / \mathrm{s}$ or greater, the cumulative horizontal drag force can reach one half of the maximum tension of the tether. Tether safety is critical to an ultra-high-altitude tethered balloon (Menke, 1967). Fig. 6 shows the breaking length (longest length that can be sustained under its own weight) of six fiber materials: nylon, Kevlar, Vectran, ultra-high-molecular-weight polyethylene (UHMWPE), Zylon, and carbon fiber. After considering factors such as cost, service conditions, strength, and creep, we selected the UHMWPE-DM20 fiber manufactured by the DSM Company in the Netherland for subsequent analysis. Although the breaking length of the fiber was $316 \mathrm{~km}$ and it has no advantages over high-strength UHMWPESK99 and high-strength aramid fiber, the fiber has superior anti-creep and anti-UV-aging properties that make it ideal for stratospheric tethered balloon applications. Table 1 shows the parameters of the cables made of UHMWPEDM20 fibers. As shown, the breaking length of the cable was $40 \%$ lower when compared to the breaking length of the corresponding fiber. We used the cable parameters in the subsequent analysis.

Launch and recovery of the tandem-style tethered balloon system do indeed face greater challenges. An offshore location would be a better test site and is worth attempting (Akita 2012). For land-based launches, we should conduct the launch in low-wind meteorological windows chosen with the aid of meteorological forecasting and sounding balloons. As for recovery, the payloads can only be parachuted down like that of high altitude balloons, but there must not be obstacles such as power transmission lines for the landing of the tether.

\section{Static response of system}

In this section, we derive the static equilibrium control equation of the tandem tethered balloon shown in Fig. 5, explain its working principle, and analyze the improvements of the tether safety factor and wind-resistant capabilities of the tandem tethered balloon over those of a single balloon by comparison with the actual model. 


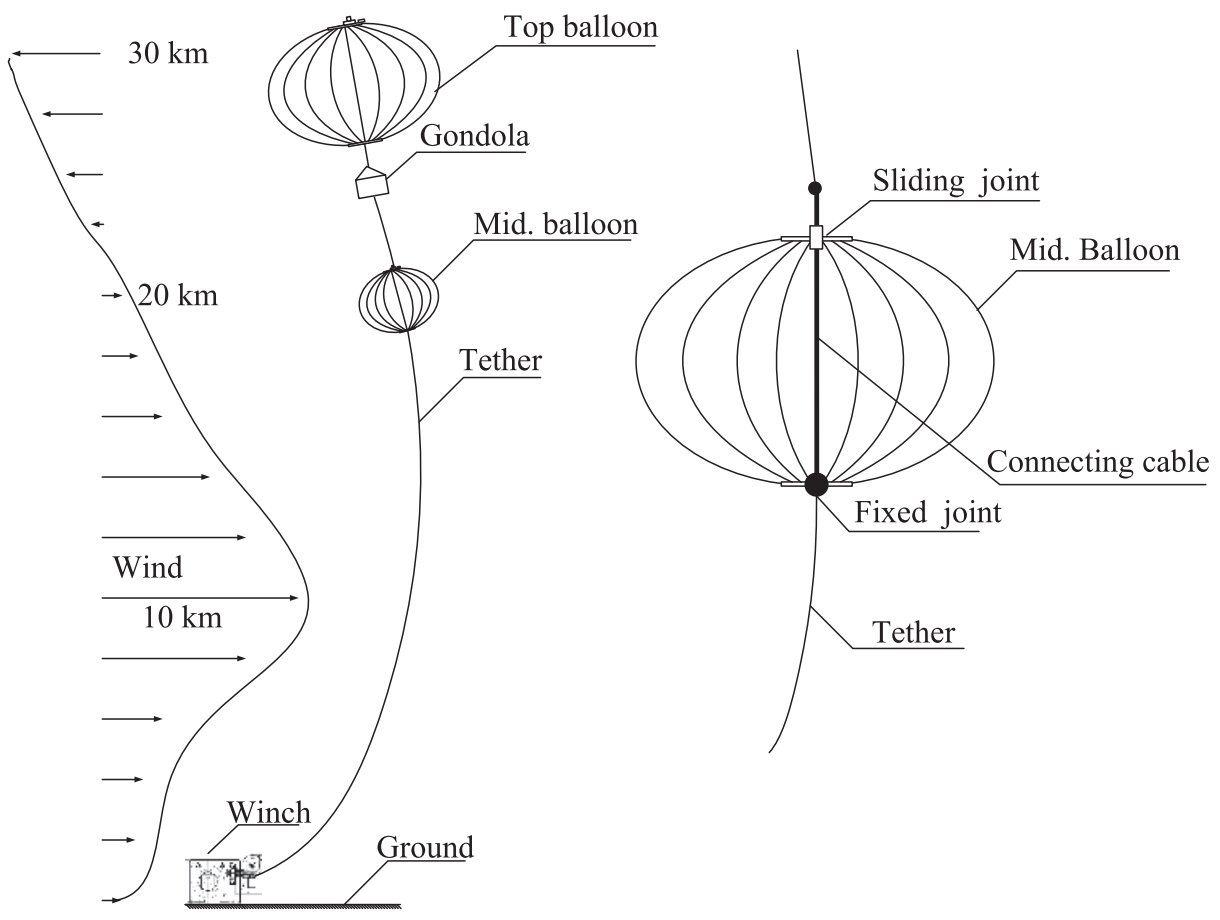

Fig. 5. Tandem style tethered balloon structure.

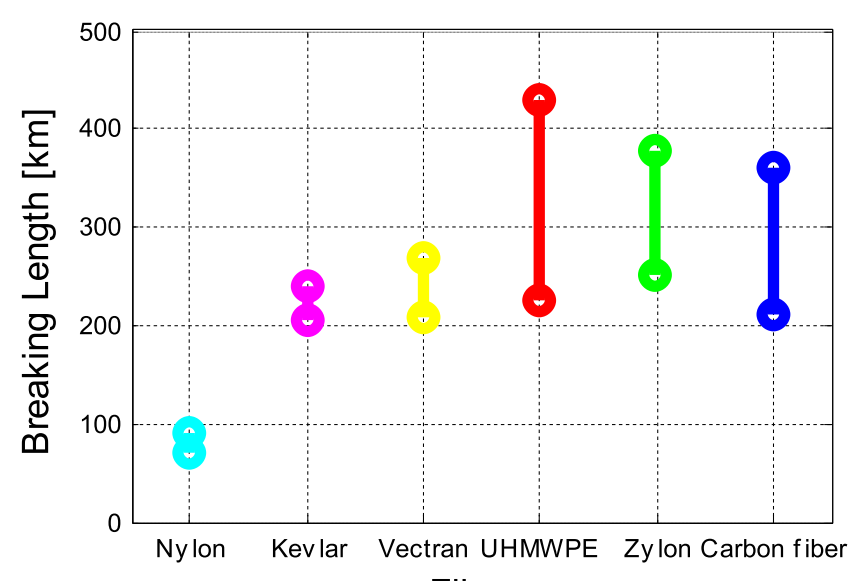

Fibers

Fig 6. Comparison of breaking lengths of high-strength fibers.

Table 1

Parameters of DM20 cables.

\begin{tabular}{llllll}
\hline Tether diameter $(\mathrm{mm})$ & 6 & 8 & 10 & 12 & 15 \\
\hline Linear density $(\mathrm{g} / \mathrm{m})$ & 22.3 & 44.5 & 63.0 & 90.0 & 134.0 \\
Breaking force $(\mathrm{kg})$ & 4107 & 8030 & 11,309 & 16,157 & 23,736 \\
Breaking length $(\mathrm{km})$ & 184.2 & 180.4 & 179.5 & 179.5 & 177.1 \\
\hline
\end{tabular}

\subsection{Derivation of governing equations}

The forces on the balloon are shown in Fig. 7, where $\boldsymbol{B}$ is the buoyancy of the balloon, $\boldsymbol{W}_{\boldsymbol{b}}$ is the weight of the balloon and the payload, $\boldsymbol{D}_{\boldsymbol{b} l}$ is the aerodynamic lift of the balloon, $\boldsymbol{D}_{\boldsymbol{b} \boldsymbol{d}}$ is the aerodynamic resistance of the balloon, $\boldsymbol{F}$ is the tension in the tether connected to the bottom of the balloon, and $i$ is the serial number of the balloon.

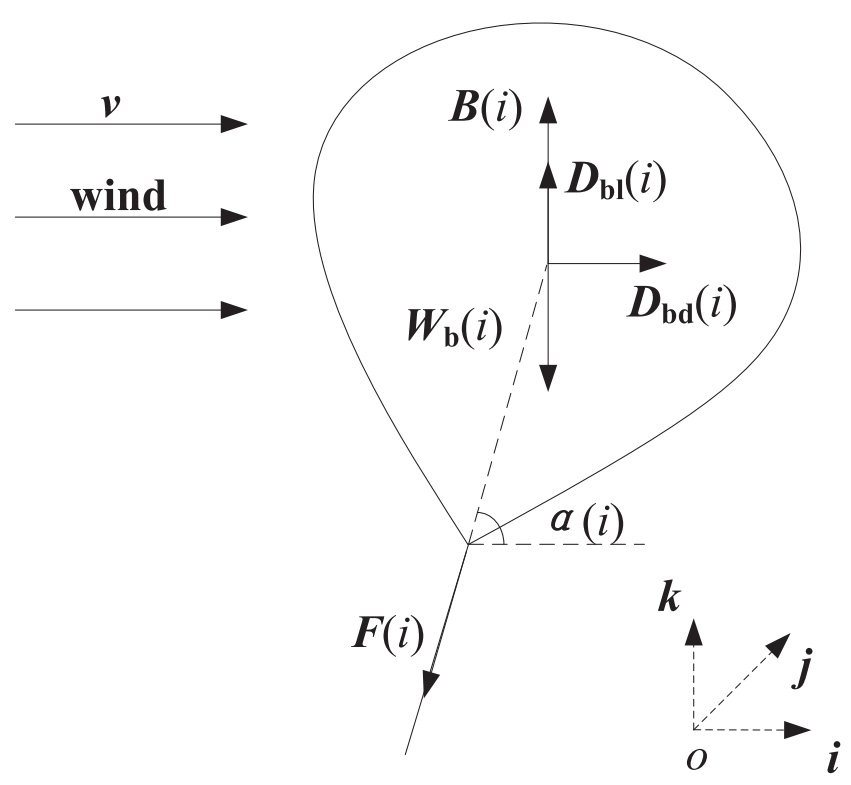

Fig. 7. Forces on the balloon.

The force equation of a balloon at steady state is as follows:

$$
\boldsymbol{F}(i)=\boldsymbol{D}_{\boldsymbol{b l}}(i)+\boldsymbol{D}_{\boldsymbol{b d}}(i)+\boldsymbol{B}(i)-\boldsymbol{W}_{\boldsymbol{b}}(i),
$$

where

$$
\begin{aligned}
& \boldsymbol{B}=\left(\rho_{a i r}-\rho_{h e}\right) V \boldsymbol{k}, \\
& \boldsymbol{D}_{\boldsymbol{b l}}=q_{b} s_{b} C_{b l} \boldsymbol{k}, \\
& \boldsymbol{D}_{\boldsymbol{b} \boldsymbol{d}}=q_{b} s_{b} C_{b d}(\cos \varphi \boldsymbol{i}+\sin \varphi \boldsymbol{j}) .
\end{aligned}
$$


In these equations, $V$ is the volume of the balloon, $\rho_{\text {air }}$ is the atmospheric density at the altitude of the balloon, $\rho_{h e}$ is the density of the helium gas in the balloon, $q_{b}$ is the dynamic pressure of the balloon, and $s_{b}$ is the characteristic area of the balloon, which is proportional to $V^{2 / 3}, C_{b l}$ is the aerodynamic lift coefficient, $C_{b d}$ is the aerodynamic resistance coefficient of the balloon, and $\varphi$ is the angle between the wind direction and the $i$-axis. The dynamic pressure $q_{b}$ of the balloon is as follows:

$q_{b}=\frac{1}{2} \rho_{\text {air }} v_{\text {air }}^{2}$

where $v_{\text {air }}$ is the wind speed at the altitude of the balloon.

The forces on a tether element are shown in Fig. 8, where $\boldsymbol{T}(\mathbf{s})$ and $\boldsymbol{T}(\mathbf{s}+\mathbf{d s})$ represent the tension at the upper and lower ends of the tether element, respectively, $\boldsymbol{D}_{\boldsymbol{n}}(\mathbf{s})$ is the aerodynamic force on the tether element, $\lambda$ is the density of the tether, and $d s$ is the length of the tether element.

The equilibrium relationship of the tether element is given by

$\boldsymbol{T}(s+d s)=\boldsymbol{T}(s)+\boldsymbol{D}_{\boldsymbol{n}}(s)-(\lambda g d s) \boldsymbol{k}$

The aerodynamic force on the tether element can be calculated using the following formula:

$\boldsymbol{D}_{\boldsymbol{n}}=\frac{1}{2} C_{n} \rho_{\text {air }} d S_{t}\left|{ }^{o} \boldsymbol{v}_{\text {air }}-\left({ }^{o} \boldsymbol{v}_{\text {air }}-\boldsymbol{i}^{\prime}\right) \boldsymbol{i}^{\prime}\right|\left({ }^{o} \boldsymbol{v}_{\text {air }}-\left({ }^{o} \boldsymbol{v}_{\text {air }}-\boldsymbol{i}^{\prime}\right) \boldsymbol{i}^{\prime}\right)$,

where $d S_{t}$ is the characteristic area of the tether element, and $C_{n}$ is the normal drag coefficient of the tether.

The coordinate system $o^{\prime}{ }^{\prime}$ ' $j$ ' $k$ ' is the coordinate system of the tether element, and $\boldsymbol{i}$ ' is the tangent direction of the tether. This coordinate system is obtained by first rotating the global coordinate system oijk around the $\boldsymbol{k}$-axis by an angle $\alpha$ and then rotating by an angle $(-\theta)$ about the $\boldsymbol{j}$-axis of the new coordinate system.

The transformation relationship between the two coordinate systems is expressed as follows:

$\left[\begin{array}{l}\boldsymbol{i} \\ \boldsymbol{j} \\ \boldsymbol{k}\end{array}\right]=o^{\prime} o \boldsymbol{R}\left[\begin{array}{l}\boldsymbol{i}^{\prime} \\ \boldsymbol{j}^{\prime} \\ \boldsymbol{k}^{\prime}\end{array}\right]$
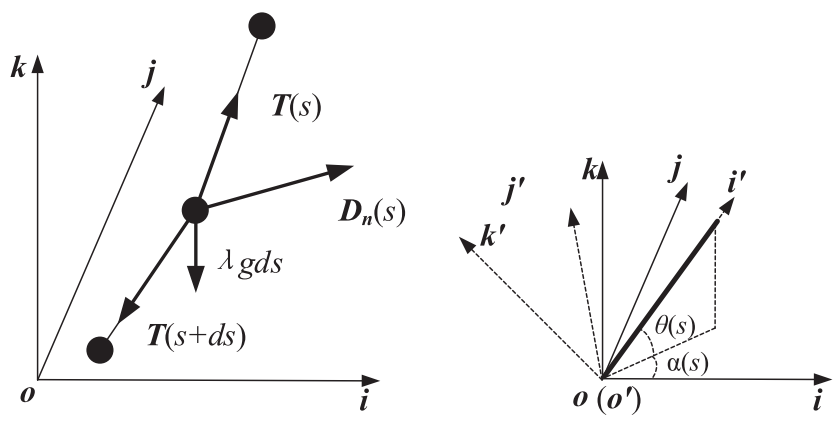

Fig. 8. Forces on a tether element and the coordinate systems. where

$$
\begin{aligned}
& o^{\prime} o \boldsymbol{R}=\boldsymbol{R}(k, \alpha) \boldsymbol{R}(j,-\theta), \\
& \boldsymbol{R}(k, \alpha)=\left[\begin{array}{ccc}
\cos \alpha & -\sin \alpha & 0 \\
\sin \alpha & \cos \alpha & 0 \\
0 & 0 & 1
\end{array}\right], \\
& \boldsymbol{R}(j,-\theta)=\left[\begin{array}{ccc}
\cos \theta & 0 & -\sin \theta \\
0 & 1 & 0 \\
\sin \theta & 0 & \cos \theta
\end{array}\right] .
\end{aligned}
$$

Based on Eq. (6), the equilibrium relationship of the tether element connecting the middle balloon is given by

$\boldsymbol{T}(s+d s)=\boldsymbol{T}(s)+\boldsymbol{D}_{\boldsymbol{n}}(s)+\boldsymbol{F}(2)-(\lambda g d s) \boldsymbol{k}$.

As an upper boundary condition, the tension at the top of the first element at the top of the tether is equal to the pull on the balloon:

$\boldsymbol{T}(0)=\boldsymbol{F}(1)$

Solving Eqs. (6) and (12) using the above values of the boundary conditions, the tension $\boldsymbol{T}$ of each tether element, the angle $\theta$ between the tether element and the horizontal plane, and the angle $\alpha$ between the $i$-axis and the projection of the tether element in the $i j$ plane are obtained.

The position of each tether element may be calculated with the following formulas so that the shape of the three-dimensional profile of the tether can be obtained:

$\left\{\begin{array}{l}x=x_{b}-\int_{0}^{s} \cos \theta(s) \cos \alpha(s) d s \\ y=y_{b}-\int_{0}^{s} \cos \theta(s) \sin \alpha(s) d s \\ z=z_{b}-\int_{0}^{s} \sin \theta(s) d s\end{array}\right.$

In the above calculations, the buoyancy and the aerodynamic force of the balloon and the aerodynamic force of the tether are all related to the atmospheric density at the altitude in question. For the atmospheric density below $32 \mathrm{~km}$, we used the United States Standard Atmospheric Model 1976 (US St. Atmosphere, 1976), and its variation with altitude $h$ can be calculated from the following formula:

$\rho_{\text {air }}=\left\{\begin{array}{cc}1.225(1-0.0065 h / 288.15)^{4.256} & 0 \leqslant h \leqslant 11000 \mathrm{~m} \\ 0.3672 \exp (-(h-11000) / 6341.62) & 11000 \leqslant h \leqslant 20000 \mathrm{~m} \\ 0.0889(1+0.0010 \cdot(h-20000) / 216.65)^{-35.163} & 20000 \leqslant h \leqslant 32000 \mathrm{~m}\end{array}\right.$

\subsection{Static analysis results for single and tandem balloons}

We now compare and analyze the profile shape and tension of the tether for the four types of models shown in Table 2 using the analysis method described above. The analysis results are used to explain the working principle of the tandem style ultra-high-altitude tethered balloon (see Table 3). The model parameters are obtained from the design method presented in Section 4. The tether safety 
Table 2

Model parameters.

\begin{tabular}{|c|c|c|c|c|}
\hline Model & Single balloon model S1 & Single balloon model S2 & Tandem model T1 & Tandem model T2 \\
\hline Target altitude & $18 \mathrm{~km}$ & $30 \mathrm{~km}$ & $30 \mathrm{~km}$ & $30 \mathrm{~km}$ \\
\hline Payload weight & $500 \mathrm{~kg}$ & $500 \mathrm{~kg}$ & $500 \mathrm{~kg}$ & $500 \mathrm{~kg}$ \\
\hline Ground altitude & $1440 \mathrm{~m}$ & $1440 \mathrm{~m}$ & $1440 \mathrm{~m}$ & $1440 \mathrm{~m}$ \\
\hline Balloon volume & $57,612 \mathrm{~m}^{3}$ & $452,062 \mathrm{~m}^{3}$ & $452,062 \mathrm{~m}^{3}$ & $407,589 \mathrm{~m}^{3}$ \\
\hline Balloon max diameter & $54.6 \mathrm{~m}$ & $108.5 \mathrm{~m}$ & $108.5 \mathrm{~m}$ & $104.8 \mathrm{~m}$ \\
\hline Balloon height & $32.8 \mathrm{~m}$ & $65.1 \mathrm{~m}$ & $65.1 \mathrm{~m}$ & $62.9 \mathrm{~m}$ \\
\hline Balloon weight & $433 \mathrm{~kg}$ & $1695 \mathrm{~kg}$ & $1695 \mathrm{~kg}$ & $1582 \mathrm{~kg}$ \\
\hline Middle balloon volume & / & / & $14,147 \mathrm{~m}^{3}$ & $14,209 \mathrm{~m}^{3}$ \\
\hline Middle balloon max diameter & / & / & 34.18 & 34.23 \\
\hline Middle balloon height & & & 20.51 & 20.54 \\
\hline Middle balloon weight & / & / & $172.9 \mathrm{~kg}$ & $173.4 \mathrm{~kg}$ \\
\hline Tether length between the two balloons & / & / & $10,174 \mathrm{~m}$ & $10,200 \mathrm{~m}$ \\
\hline$C_{b n}$ & 0.53 & 0.53 & 0.53 & 0.53 \\
\hline$C_{b l}$ & 0.1 & 0.1 & 0.1 & 0.1 \\
\hline Tether diameter & $12 \mathrm{~mm}$ & $12 \mathrm{~mm}$ & $12 \mathrm{~mm}$ & $12 \mathrm{~mm}$ \\
\hline Linear density of tether & $90 \mathrm{~g} / \mathrm{m}$ & $90 \mathrm{~g} / \mathrm{m}$ & $90 \mathrm{~g} / \mathrm{m}$ & $90 \mathrm{~g} / \mathrm{m}$ \\
\hline Minimum breaking force & $16,157 \mathrm{~kg}$ & $16,157 \mathrm{~kg}$ & $16,157 \mathrm{~kg}$ & $16,157 \mathrm{~kg}$ \\
\hline$C_{n}$ & 1.17 & 1.17 & 1.17 & 1.17 \\
\hline
\end{tabular}

Table 3

Comparison of model analysis results.

\begin{tabular}{|c|c|c|c|c|}
\hline & Model S1 & Model S2 & Model T1 & Model T2 \\
\hline Maximum tension $(\mathrm{kg})$ & 5211.5 & 5211.6 & 5211.6 & 4615.9 \\
\hline$\theta\left(h_{\text {gnd }}\right)$ at $70 \%$ wind $\left({ }^{\circ}\right)$ & 56.4 & 64.1 & 71.4 & 66.6 \\
\hline$\theta\left(h_{\text {gnd }}\right)$ at $80 \%$ wind $\left(^{\circ}\right)$ & 47.5 & 53.9 & 63.7 & 57.3 \\
\hline$\theta\left(h_{\text {gnd }}\right)$ at $\max$ wind $\left(^{\circ}\right)$ & / & / & 28.5 & 13.9 \\
\hline
\end{tabular}

factor $\left(K_{S F}\right)$ for models $\mathrm{S} 1, \mathrm{~S} 2$, and T1 were all equal to 3.1. For model T2, $K_{S F}$ was equal to 3.5.

$K_{S F}$ is defined by the following formula:

$K_{S F}=\frac{F_{\min }^{\text {tether }}}{T_{\max }}$,

where $F_{\min }^{\text {tether }}$ is the minimum breaking force of the tether, and $T_{\max }$ is the maximum operating tension of the tether. $K_{S F}$ works against the wind-resistant capabilities of the system. The wind-resistant capabilities of the system may be represented by the angle $\theta\left(h_{\text {gnd }}\right)$ between the ground end of the tether and the horizontal plane. The larger $\theta\left(h_{g n d}\right)$ is, the better the wind-resistant capabilities become. When $\theta\left(h_{g n d}\right)$ is too small, the tether will touch the ground and the balloon will not be able to stay aloft under adverse conditions, such as excessive wind.

The factor $K_{S F}$ reflects the degree of safety of the tether operation. The value of $K_{S F}$ for a traditional tethered balloon is around 4 (Carroll, 1985). The analysis results for single-balloon schemes $\mathrm{S} 1$ and $\mathrm{S} 2$ show that when $K_{S F}$ was increased to more than 3 , the balloon was unable to remain airborne under high-wind conditions. Without reducing the wind-resistant capabilities of the system, it is challenging to increase the $K_{S F}$ values of ultra-highaltitude tethered balloons.

The above models were analyzed numerically. Figs. 9-12 show the tether profiles under different wind fields and changes in the tether tension under the maximum wind field for the four different models. In the profile graphs, the sources of the wind field are $70 \%, 80 \%, 90 \%$, and $100 \%$ of the maximum wind speed, and the average wind direction is shown in Fig. 4. The figures only show the tether displacement on the main displacement plane Y-Z. In the tether tension graphs, $T$ is the tether tension, and $T_{x}, T_{y}$, and $T_{z}$ are components of the tether tension in the $i, j$, and $k$ directions of the global coordinate system, respectively.

The profile graphs show that, as the wind speed increases, the tether displacements of the four models increase rapidly and non-linearly. Figs. 9 and 10 show that models S1 and S2 can accommodate a $90 \%$ wind speed environment, but when the wind speed increases to the maximum speed, models S1 and S2 have difficulties at an elevation of $1760 \mathrm{~m}$. At this altitude, the tether only undergoes horizontal displacement, and $T_{Z}$ decreases to 0 , indicating that the system buoyancy is insufficient to support the weight of the tether cable. The main reason for this problem is that, as Eq. (7) indicates, the tether aerodynamic force increases with the square of the wind speed. This causes the horizontal displacement of the tether to increase accordingly and increases the length and weight of the tether. When the wind speed is excessive, the increased weight of the tether will reduce the vertical component of the tether tension to zero and eventually cause the system to fail due to insufficient buoyancy. 

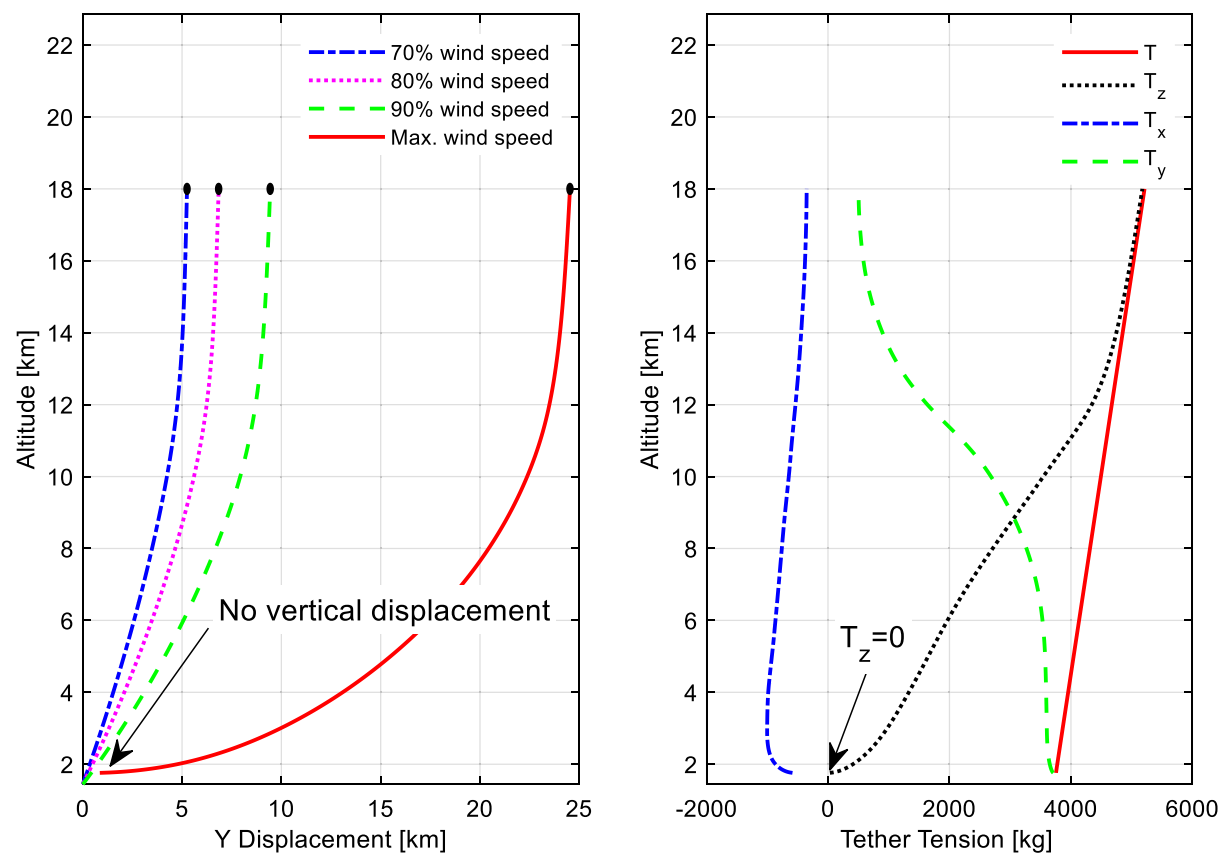

Fig. 9. Profile shapes of tether under different wind fields and tether tensions under maximum wind field for Model S1.
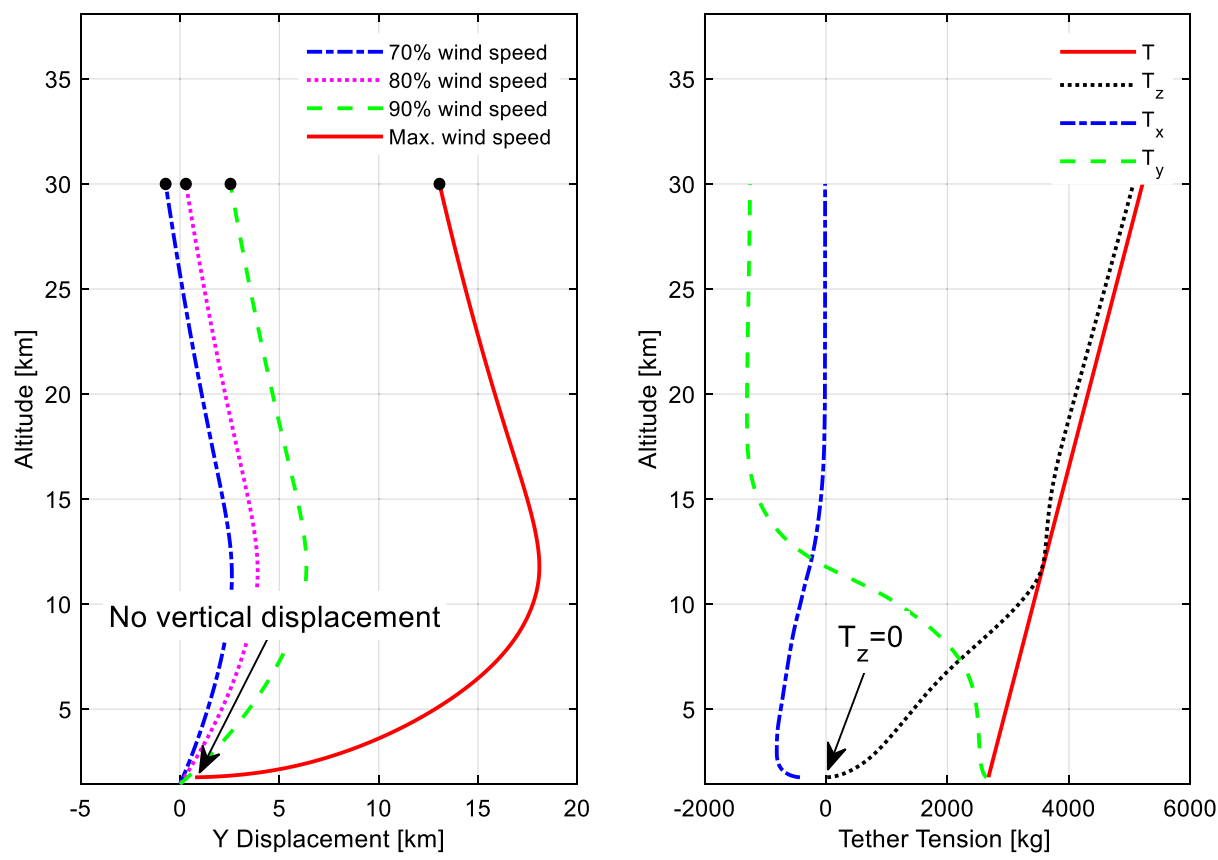

Fig. 10. Profile shapes of tether under different wind fields and tether tensions under maximum wind field for Model S2.

On the basis of Model S2, Model T1 is able to resist the maximum specified wind speed if a middle balloon is added with a volume of $3.1 \%$ of that of the top balloon at $20 \mathrm{~km}$, without changing $K_{S F}$. Although the added middle balloon provides only $900 \mathrm{~kg}$ of net buoyancy, by reducing the horizontal displacement of the tether, the tether weight is reduced, and $T_{Z}$ on the ground end reaches $1376 \mathrm{~kg}$, providing a certain degree of wind resistance.

By suitably increasing the $K_{S F}$ of Model T1, we obtained Model T2. A comparison of Models T2 and S1 shows that the maximum operating tension of the tether of $\mathrm{T} 2$ is reduced from $5211.6 \mathrm{~kg}$ for $\mathrm{S} 2$ to $4615.9 \mathrm{~kg}$, and the corresponding $K_{S F}$ increases from 3.1 to 3.5. Meanwhile, Model T2 can resist wind speeds that Model S1 cannot. The results showed that tandem models can simultaneously increase $K_{S F}$ and improve the wind-resistant capabilities compared to those of the single balloon models.

We next analyzed the principle by which tandem tethered balloons increase $K_{S F}$ and the wind-resistant capabilities. The following formula is an expression of $\theta\left(h_{g n d}\right)$ : 

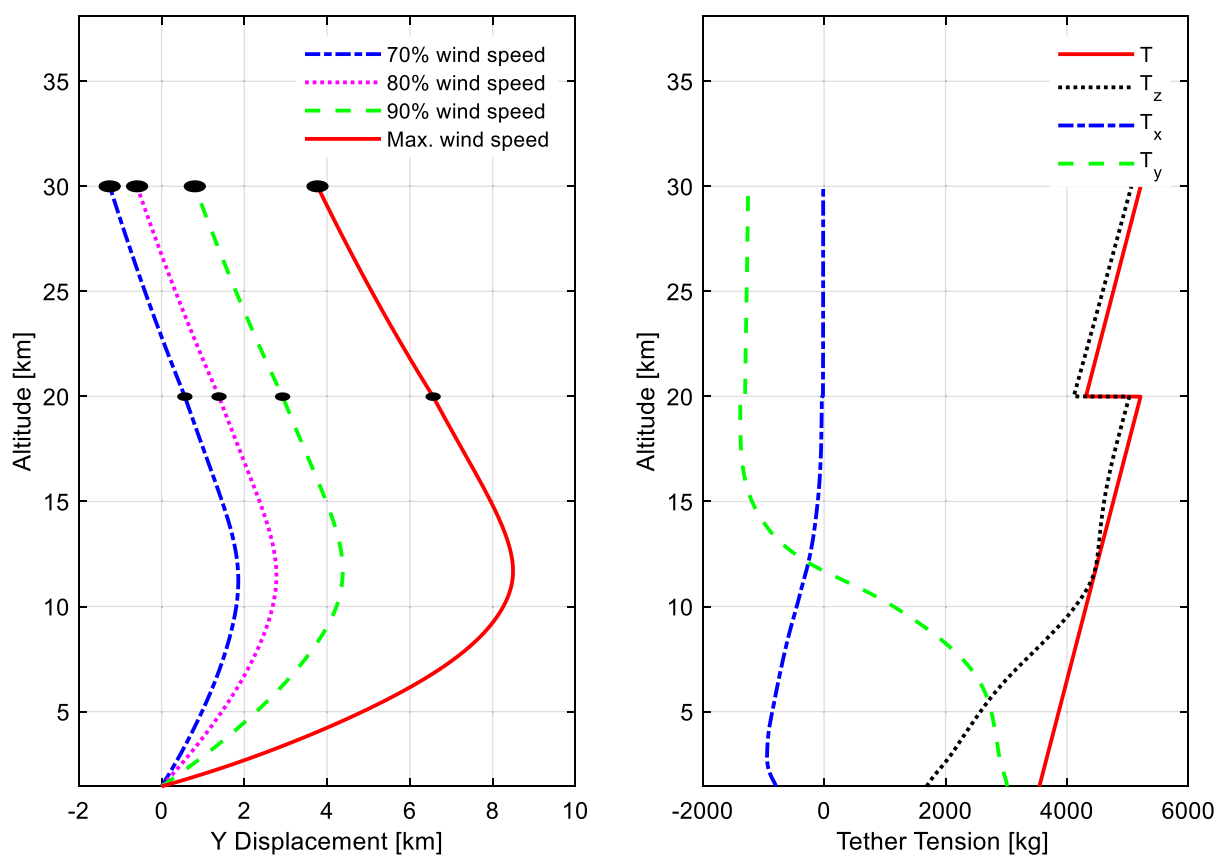

Fig. 11. Profile shapes of tether under different wind fields and tether tensions under maximum wind field for Model T1.
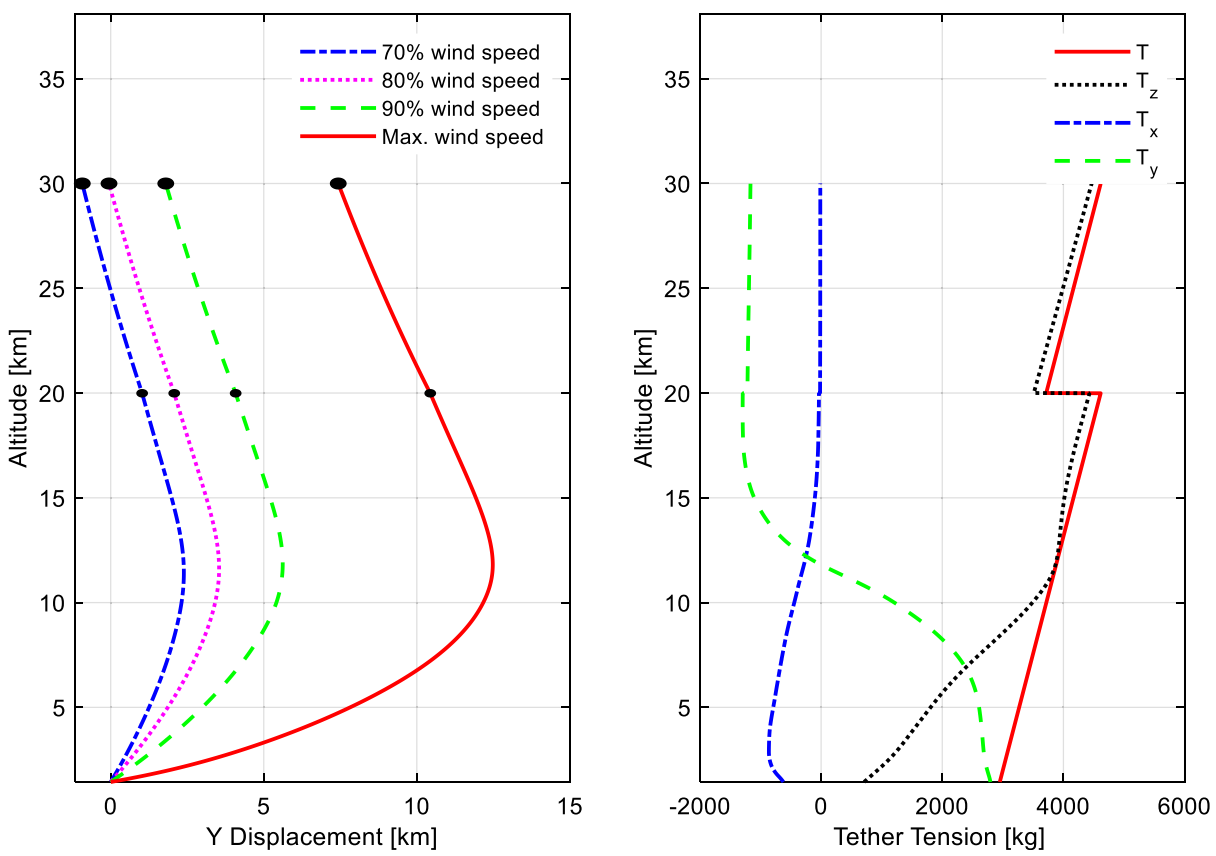

Fig. 12. Profile shapes of tether under different wind fields and tether tensions under maximum wind field for Model T2.

$\tan \theta\left(h_{g n d}\right)=\frac{T_{z}\left(h_{g n d}\right)}{\sqrt{T_{x}^{2}\left(h_{g n d}\right)+T_{y}^{2}\left(h_{g n d}\right)}}$

The larger the value of $\theta\left(h_{\text {gnd }}\right)$ is, the smaller the horizontal displacement of the tether is, and the greater the wind-resistant capabilities are.

A tandem ultra-high-altitude tethered balloon improves the wind-resistant capabilities in two aspects: increasing $T_{z}\left(h_{g n d}\right)$ and decreasing $T_{y}\left(h_{g n d}\right)$. A comparison of the ten- sion curves of tandem Models $\mathrm{Tl}$ and $\mathrm{T} 2$ and single balloon Models S1 and S2 shows that, with the middle balloon in place, $T_{Z}\left(h_{g n d}\right)$ is increased, which increases $\theta$ without reducing $K_{S F}$. Furthermore, a comparison of the tension curves of Models S1 and T1 shows that with Model S1 operating at $18 \mathrm{~km}, T_{x}\left(h_{\text {gnd }}\right)$ reaches $3709 \mathrm{~kg}$. With Model $\mathrm{T} 1$ operating at $30 \mathrm{~km}$, due to the opposite direction characteristics of high and low altitude winds, the drag generated by the tether and the drag of the top balloon partially cancel each other, so that $T_{x}$ first decreases and 


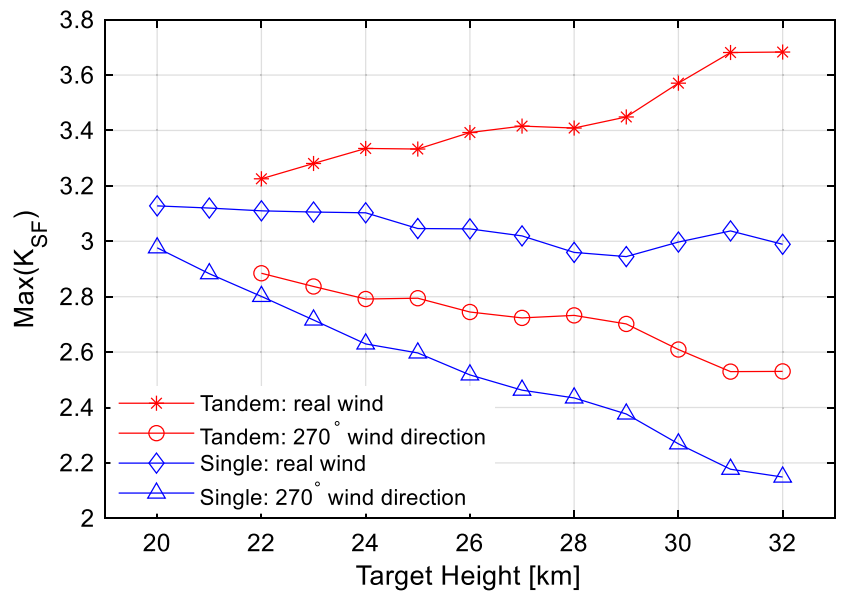

Fig. 13. Maximum $K_{S F}$ for different wind directions and operating altitudes.

then increases, lowering $T_{x}\left(h_{g n d}\right)$ to $3014 \mathrm{~kg}$. As $T_{x}$ decreases, $\theta$ further increases and improves the windresistant capabilities of the system.

To further compare the single and tandem balloon models, the maximum $K_{S F}$ that can be achieved by the two models at different operating altitudes was calculated and is denoted as $\max \left(K_{S F}\right)$. We set the value of $K_{S F}$ when $\theta$ $\left(h_{g n d}\right)$ was $10^{\circ}$ as $\max \left(K_{S F}\right)$. The wind speed used in the calculation was the maximum wind speed in Fig. 4. Analyses were conducted for two wind direction conditions: using the actual wind direction in Fig. 4 and using the constant wind direction of $270^{\circ}$. The results are shown in Fig. 13. The following conclusions can be drawn:

- For both the single and tandem balloon models, the value of $\max \left(K_{S F}\right)$ in the environment of opposite low and high altitude wind directions is greater than that in a constant wind direction environment.

- In both the constant wind direction environment and the opposite low and high altitude wind direction environments, $\max \left(K_{S F}\right)$ for the tandem balloon model is greater than that of the single balloon model.

- For a single balloon model, $\max \left(K_{S F}\right)$ decreases with increasing operating altitude. For a tandem balloon model operating in an opposite low and high altitude wind direction environment, $\max \left(K_{S F}\right)$ increases with increasing operating altitude.

\section{Design method of tandem ultra-high-altitude tethered balloon}

The design method for obtaining the model parameters shown in Table 2 is discussed in this section. The central design concept of this method is for the tether to have a constant $K_{S F}$, i.e., the tension of the tether should be kept the same at the locations of the middle and top balloons, so that the strength of the tether is used optimally. The detailed design process is shown below in Fig. 14.

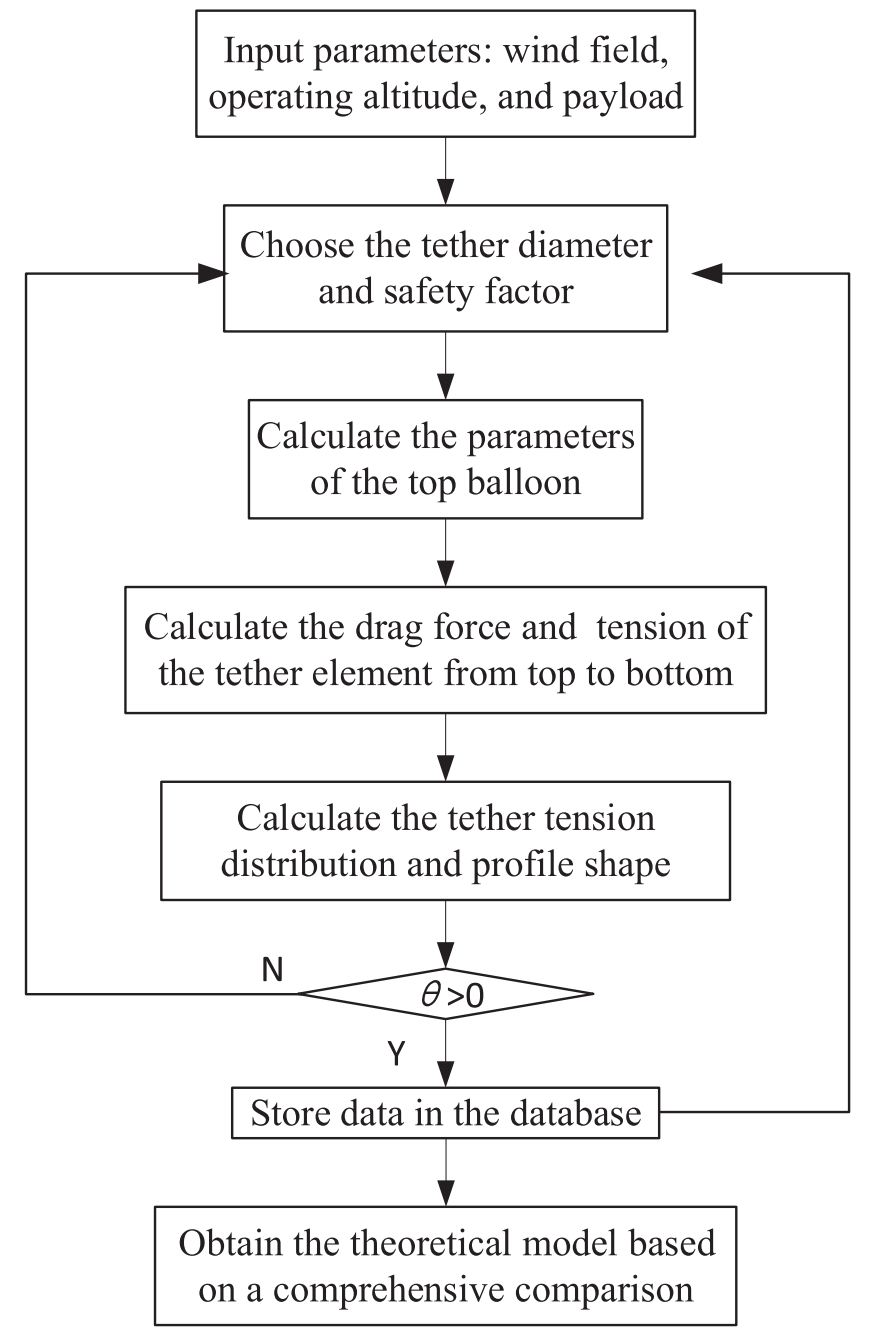

Fig. 14. System design process.

The system input parameters are the wind field, the operating altitude, and the payload (payload weight and power consumption parameters). A preliminary analysis is first made for the wind field and, based on the wind variations, a central region with low wind is selected as the operating altitude $h_{\text {mid }}$ of the middle balloon. A diameter of the tether is selected, and $K_{S F}$ is tentatively formulated for the next design analysis. From Eq. (16), the maximum allowable working tension $T_{\max }$ of the tether is obtained. The design parameters for the top balloon are then obtained from Eq. (18) based on $T_{\max }$ as the tether tension boundary. The aerodynamic resistance of the balloon $D_{b d}$, the aerodynamic lift $D_{b l}$, and the buoyancy $B$ are all functions of the balloon volume $V_{l} . W_{b}$ is the total weight of the system, including the weight of the balloon and the payload (including the weight of the power supply). For extended periods of operation, the weight of a renewable energy system also must be considered. With a known payload, the total balloon weight $W_{b}$ can also be expressed as a function of the balloon volume. Using Eq. (18), the volume $V_{l}$ of the top balloon may be obtained through iterative calculations: 
$\left(D_{b l}\left(V_{1}\right)+B\left(V_{1}\right)-W_{b}\left(V_{1}\right)\right)^{2}+D_{b d}^{2}\left(V_{1}\right)=T_{\max }^{2}$

Based on the static equilibrium equation in Section 3, the tension in the tether element is calculated from top to bottom until the operating altitude of the balloon $h_{\text {mid }}$ is reached. Parameters of the middle balloon are then designed based on the principle of a constant $K_{S F}$ in the tether and using $T_{\max }$ as the boundary of the tether tension. $T_{x}\left(h_{\text {mid }}\right), T_{y}\left(h_{\text {mid }}\right)$, and $T_{z}\left(h_{\text {mid }}\right)$ are the components in Cartesian coordinates of the tension at the lower end of the tether element at an altitude of $h_{\text {mid }}$. The middle balloon is connected at the lower end of this element. The volume of the middle balloon $V_{2}$ can be calculated iteratively as follows:

$$
\begin{gathered}
\left(D_{b d}\left(V_{2}\right) \cos \varphi\left(h_{\text {mid }}\right)+T_{x}\left(h_{\text {mid }}\right)\right)^{2}+\left(D_{b d}\left(V_{2}\right) \sin \varphi\left(h_{\text {mid }}\right)\right. \\
\left.+T_{y}\left(h_{\text {mid }}\right)\right)^{2}+\left(D_{b l}\left(V_{2}\right)+B\left(V_{2}\right)-W_{b}\left(V_{2}\right)\right. \\
\left.+T_{z}\left(h_{\text {mid }}\right)\right)^{2}=T_{\max }^{2}
\end{gathered}
$$

Continuing from top to bottom, the tension distribution of the tether is calculated. When $\theta$ is less than 0 , the buoyancy of the balloon is insufficient. In this case, $K_{S F}$ is decreased or the diameter of the tether is increased, and the tension is re-calculated until the ground is reached. The angle between the tether element and the horizontal plane is $\theta\left(h_{g n d}\right)$. The calculated results (balloon parameters, diameter of the tether, and $K_{S F}$ ) are saved to the database.

In the process described above, the different tether diameters, $K_{S F}$ values and the corresponding $\theta\left(h_{\text {gnd }}\right)$ values, the tether profile shape, and the tension distribution data are stored in a database. Finally, a comprehensive selection is made based on factors such as cost, manufacturability, and implementation difficulty.

\section{Parameter sensitivity and feasibility analysis for long- duration flight}

We now use the design method of Section 4 to analyze the effects of the tether diameter and the aerodynamic parameters of the balloon and tether on the performance of the tandem tethered balloon system and to analyze a long-duration flight of the system. The effect of the tether diameter will be optimized using different tether diameters in the design, and corresponding changes in $\max \left(K_{S F}\right)$ and the balloon volume will be analyzed.

Since the aerodynamic parameters of the tether and balloon are affected by a number of factors, such as the shape of the balloon, its surface smoothness, the attitude, and the atmospheric viscosity, they are difficult to estimate accurately. The assessment of the tether resistance coefficient $C_{n}$, the balloon resistance coefficient $C_{b d}$, and the aerodynamic lift coefficient $C_{b l}$ will therefore proceed in two ways. First, in the design optimization phase, the design of the balloon will be carried out for specific analysis parameters, and the effects of these parameters on $\max \left(K_{S F}\right)$ and the changes of the balloon volume will be analyzed for ideal conditions. Second, during an actual flight test, errors in the estimation or changes of the conditions can lead to parameter changes in the flight process. For instance, changes of the balloon attitude can lead to changes in $C_{b d}$ and $C_{b l}$. Changes in the surface condition of the tether can change $C_{n}$. During this time, the volume and the weight of the balloon would not change. To address such situations, the changes in tether tension and $\theta\left(h_{\text {gnd }}\right)$ caused by parameter changes will be analyzed. In this analysis process, the balloon volume and weight data came from the tandem tethered balloon model T1 listed in Table 2.

\subsection{Sensitivity to tether diameter}

For different tether diameters and $K_{S F}$ values, the volume of the tandem balloon is designed using the design method in Section 4 to provide a series of tandem balloon models, while at the same time obtaining parameters that characterize the wind-resistant capabilities: $\theta\left(h_{\text {gnd }}\right)$ and $K_{S F}$.

Figs. 15 and 16 show the changes of $K_{S F}, \theta\left(h_{\text {gnd }}\right)$, and the balloon volume for different tether diameters. The greater

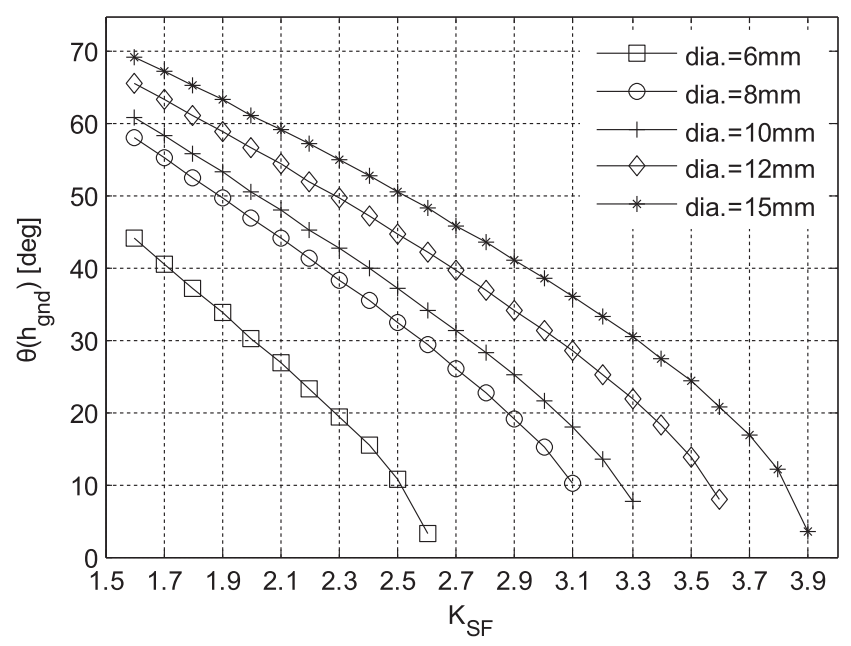

Fig. 15. Effects of different tether diameters on $K_{S F}$ and $\theta\left(h_{\text {gnd }}\right)$.

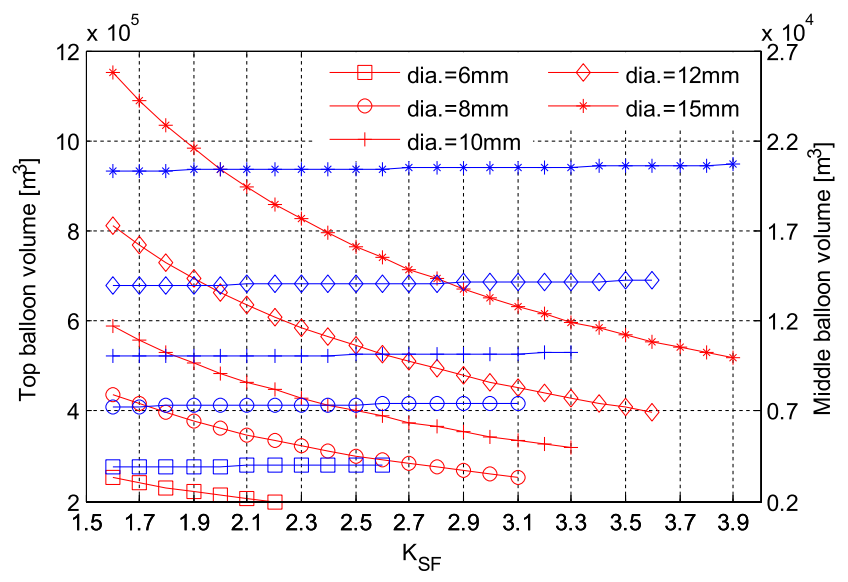

Fig. 16. Effects of different tether diameters on balloon volume (red curves represent the top balloon volume). (For interpretation of the references to colour in this figure legend, the reader is referred to the web version of this article.) 
the tether diameter is, the larger $\max \left(K_{S F}\right)$ is, and the more advantageous it is for the system security. For example, when the tether diameter is increased from 6 to $15 \mathrm{~mm}$, the value of $\max \left(K_{S F}\right)$ increases from 2.5 to 3.8 , but at the expense of a larger top balloon (red line in Fig. 16). This corresponds to a higher cost (for a larger balloon, more tether fibers, and more helium gas). Fig. 16 also shows that the volume of the middle balloon is at least one order of magnitude smaller than that of the top balloon and that, for a given tether diameter, the volume of

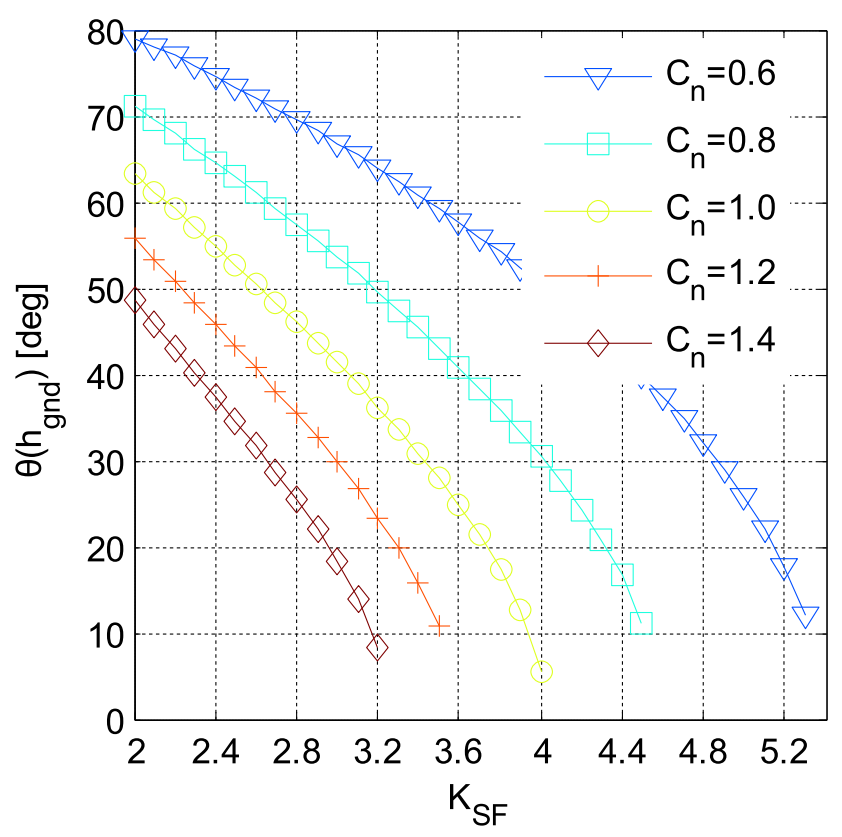

Fig. 17. Effects of $C_{n}$ on $K_{S F}$ and $\theta\left(h_{g n d}\right)$.

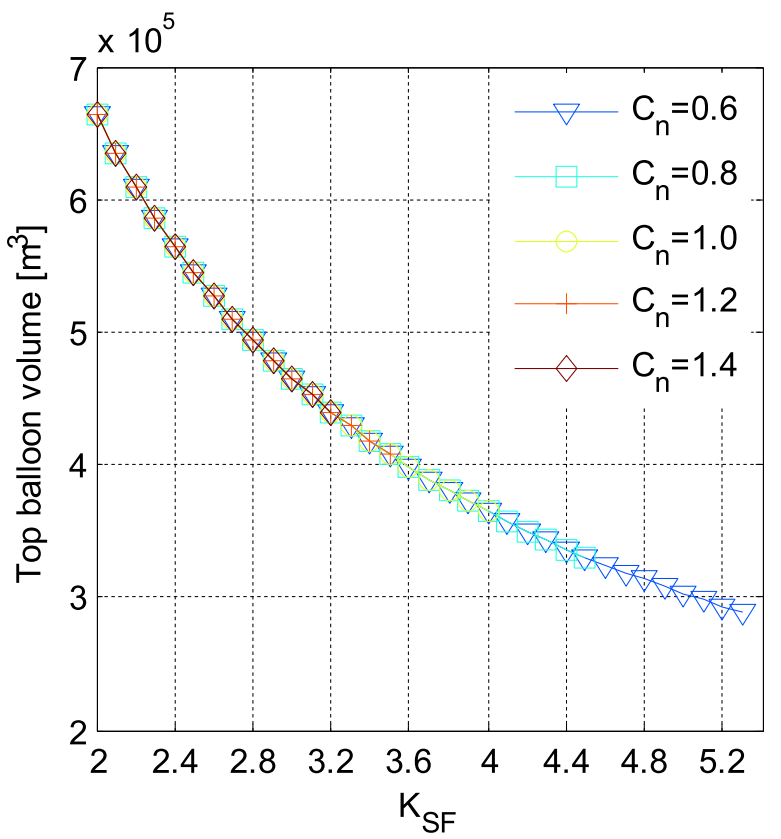

Fig. 18. Effects of $C_{n}$ on balloon volume. the middle balloon corresponding to different $K_{S F}$ values varied little (blue line in Fig. 16).

\subsection{Sensitivity of aerodynamic parameters}

The aerodynamic parameter sensitivity analysis was divided into two parts. The first part was the system design using the design method in Section 4 and the calculation of the maximum $K_{S F}$ achievable for the aerodynamic parameters. The second part was the numerical simulation of the static equilibrium equation using the method in Section 3

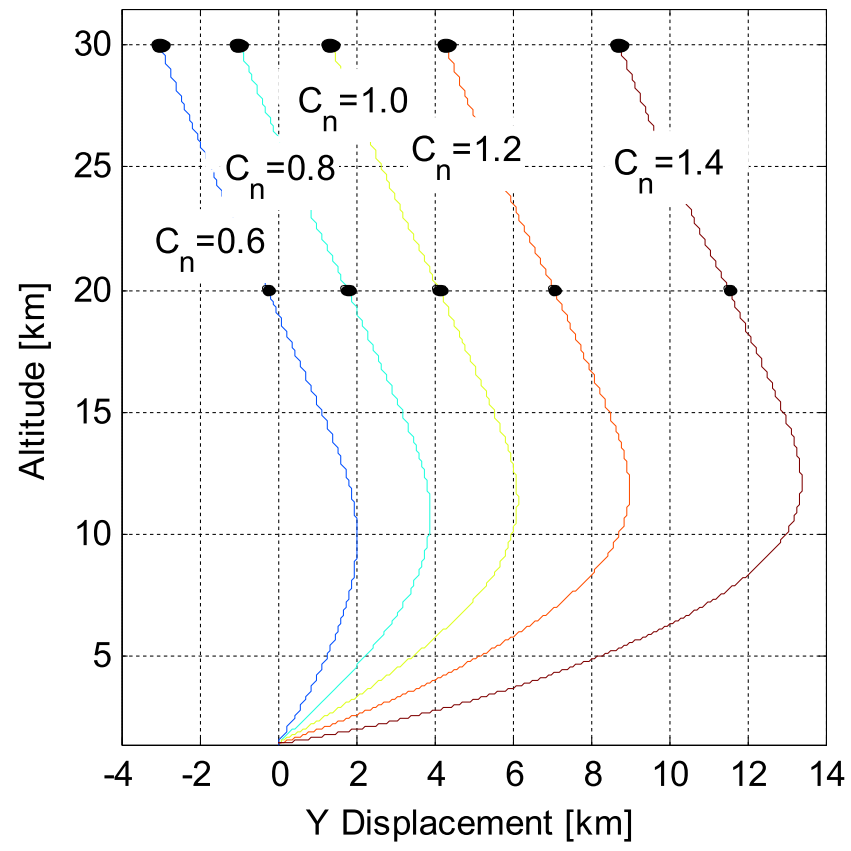

Fig. 19. Tether profiles for different $C_{n}$.
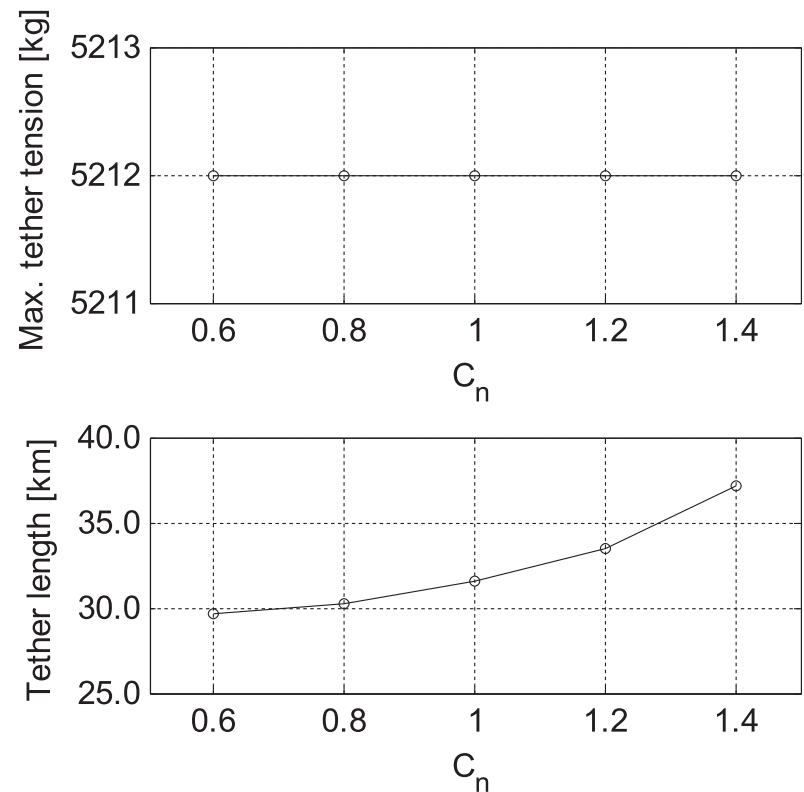

Fig. 20. Variation of maximum tether tension and length for different $C_{n}$ 
for the specific aerodynamic parameter changes of a given system and the analysis of the effects of parameter changes on the tether profile, tether length, and maximum tension.

In Figs. 17 and 18, the effects of the tether resistance coefficient $C_{n}$ are analyzed from an optimization and design perspective. The smaller the tether drag coefficient $C_{n}$ is, the greater the achievable $\max \left(K_{S F}\right)$ is through the balloon design, without increasing the volume of the top balloon. It is therefore important to reduce $C_{n}$ in the design stage by reducing the surface friction of the tether and changing the cross-sectional shape of the tether.

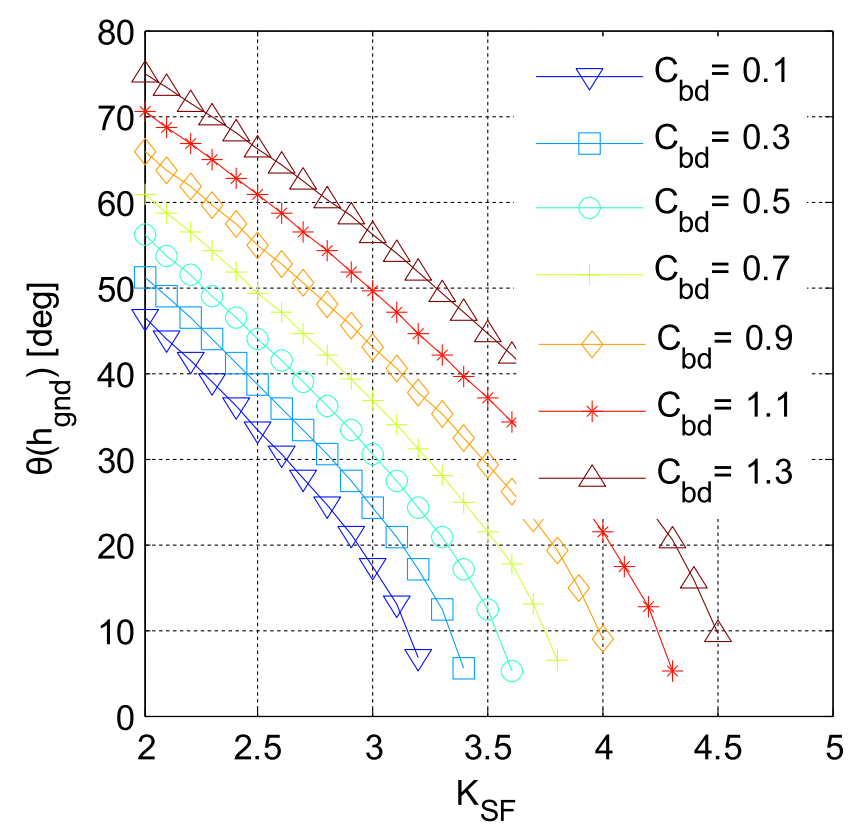

Fig. 21. Effects of $C_{b d}$ on $K_{S F}$ and $\theta\left(h_{g n d}\right)$.

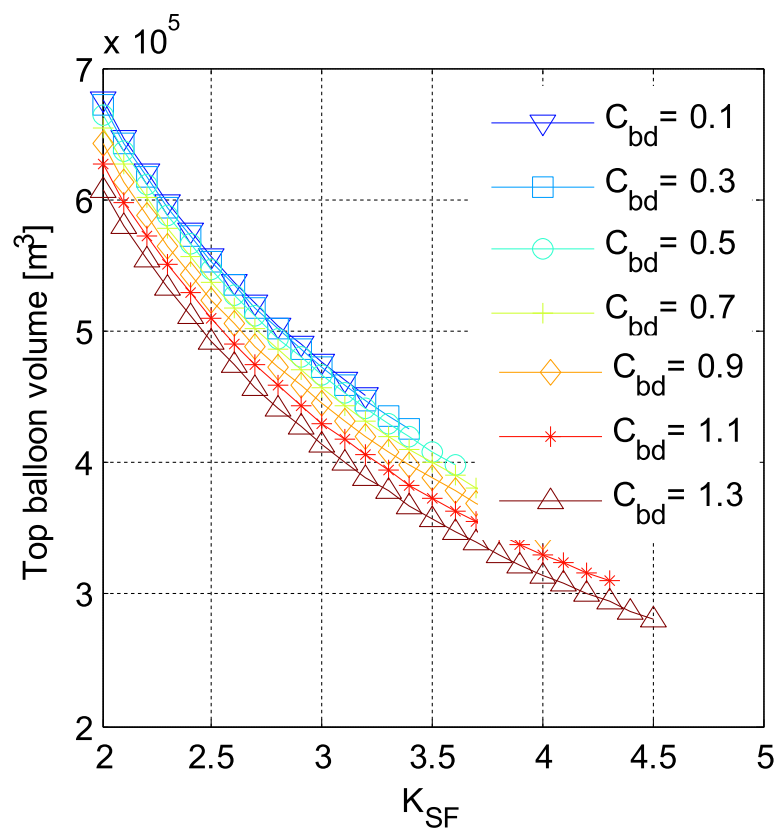

Fig. 22. Effects of $C_{b d}$ on balloon volume.
In Figs. 19 and 20, the effects of the tether resistance coefficient $C_{n}$ are analyzed from the perspective of a flight test. For a system with a fixed balloon volume, a decrease in $C_{n}$ would not change the maximum tension of the tether. The tether length needed to maintain a certain flight altitude would be reduced, the maximum drift distance of the tether would be improved, $\theta\left(h_{\text {gnd }}\right)$ would decrease, and the system's wind resistance would be enhanced.

Figs. 21 and 22 show the analysis of the effects of the balloon aerodynamic resistance coefficient $C_{b d}$ from a design optimization perspective. The figures show that the greater $C_{b d}$ is, the greater the achievable $\max \left(K_{S F}\right)$

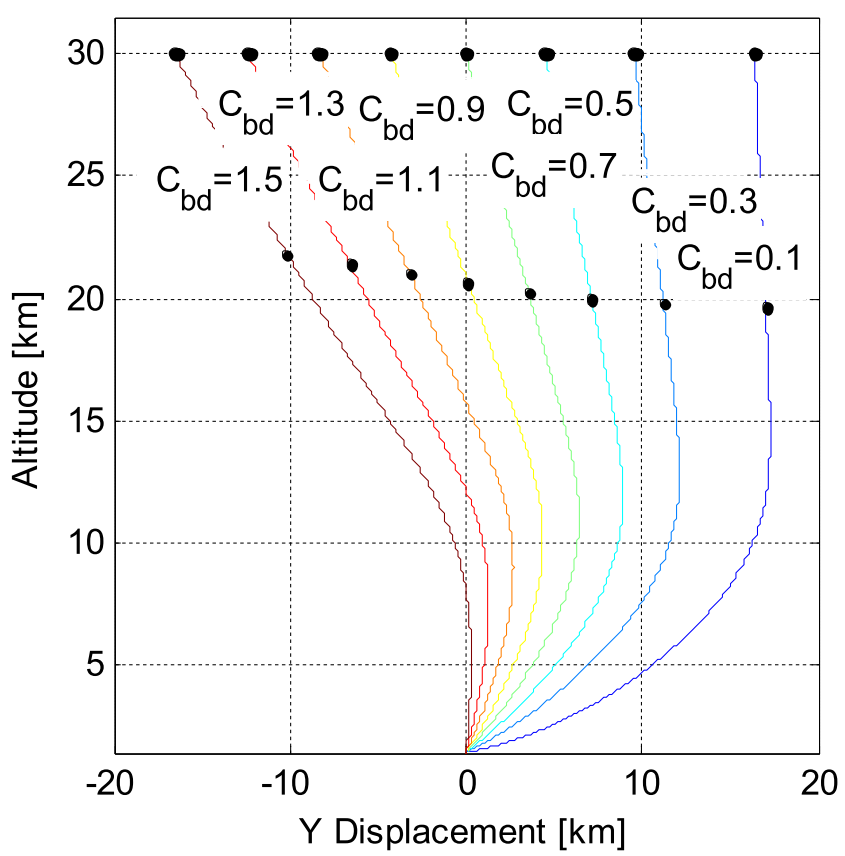

Fig. 23. Tether profiles for different $C_{b d}$.
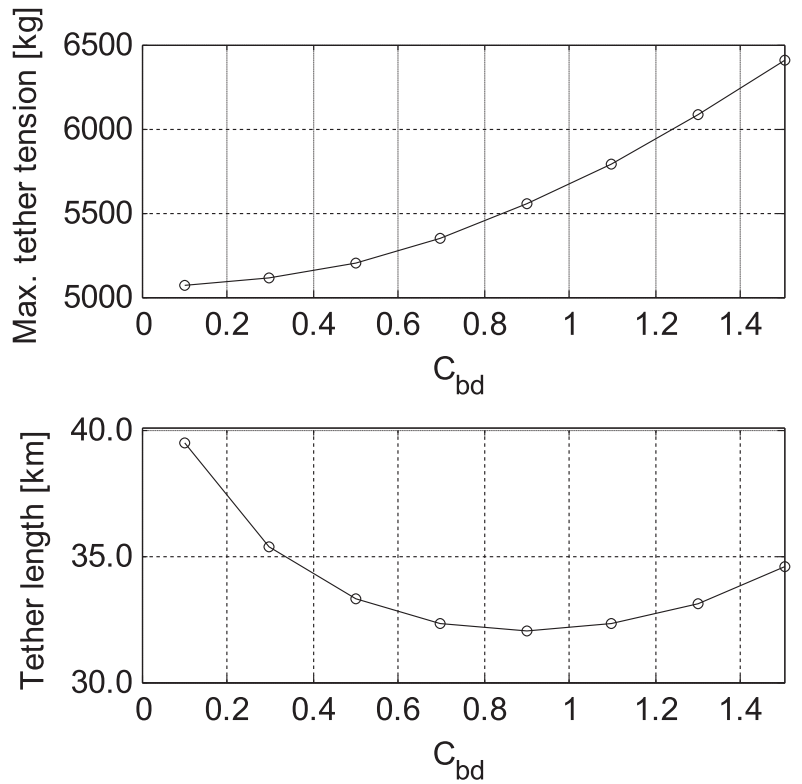

Fig. 24. Variation of maximum tether tension and length for different $C_{b d}$. 
through the balloon design is, without making substantial changes to the volume of the top balloon. For the same $K_{S F}$, the volume of the top balloon decreases slightly as $C_{b d}$ increases.

Figs. 23 and 24 show the analysis of the effects of the aerodynamic resistance coefficient $C_{b d}$ of the balloon from the perspective of a flight test. The results show that for balloons with fixed volumes, the maximum tether tension increases monotonically with increasing $C_{b d}$. It is therefore necessary to suitably amplify the $C_{b d}$ estimation during the design stage to avoid any decrease in $K_{S F}$ caused by an underestimated $C_{b d}$ and subsequent effects on the safety

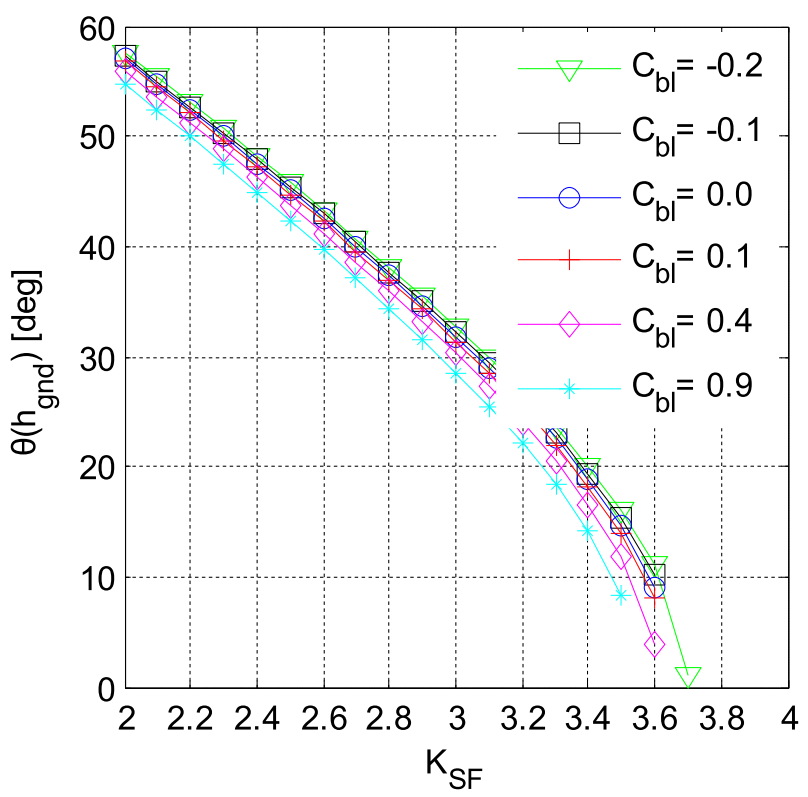

Fig. 25. Effects of $C_{b l}$ on $K_{S F}$ and $\theta\left(h_{\text {gnd }}\right)$.

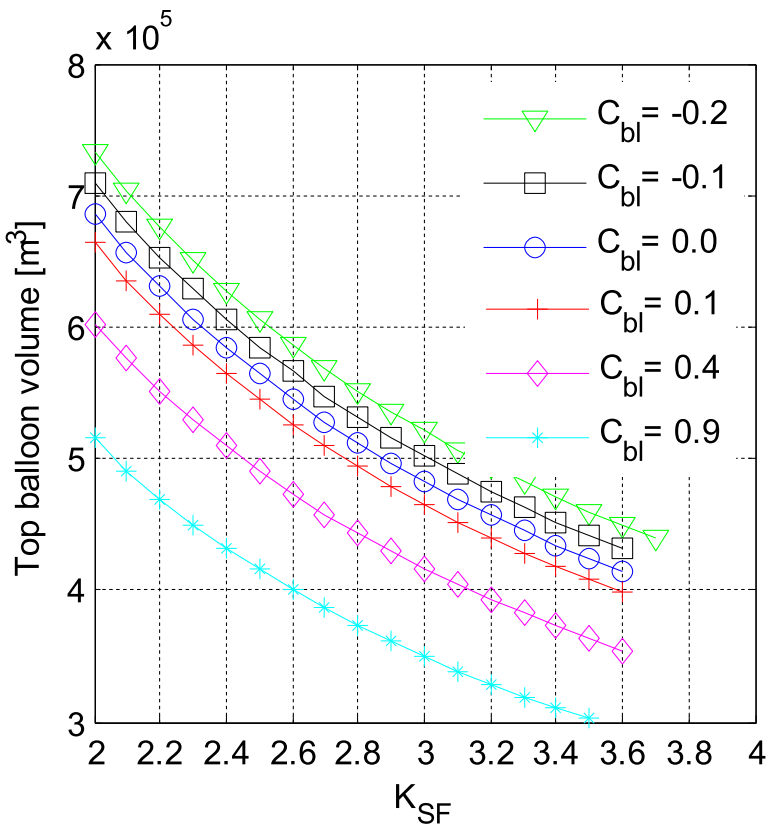

Fig. 26. Effects of $C_{b l}$ on balloon volume. of the tether. The length of the tether changes nonmonotonically with respect to $C_{b d}$, reaching a minimum when $C_{b d}$ is ca. 0.9.

Figs. 25 and 26 show the effects of the aerodynamic lift coefficient $C_{b l}$ from a design optimization perspective. Fig. 25 shows that $C_{b l}$ has very little effect on $\max \left(K_{S F}\right)$ in the design optimization stage. Fig. 26 shows that as $C_{b l}$ decreases, the volume of the top balloon increases. This indicates that the decrease in the aerodynamic lift in the design stage may be compensated for by increasing the

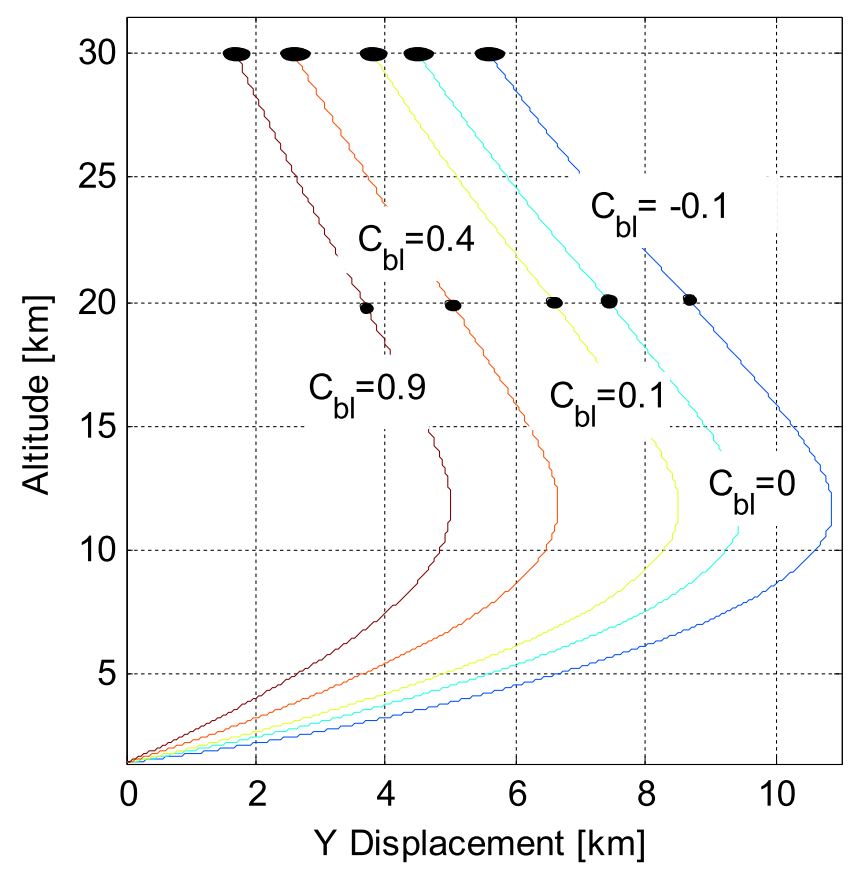

Fig. 27. Tether profile for different $C_{b l}$.
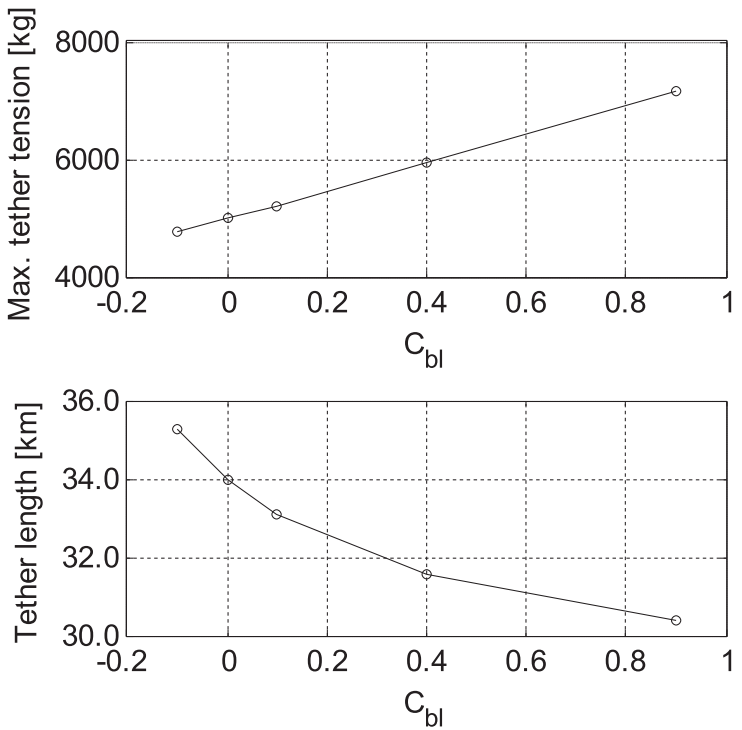

Fig. 28. Variation of maximum tether tension and length for different $C_{b l}$ 
volume of the balloon, which does not affect $\max \left(K_{S F}\right)$ significantly.

Figs. 27 and 28 show the effects of the aerodynamic lift coefficient $C_{b l}$ from a flight test perspective. In a system with a fixed-volume balloon, an increase in $C_{b l}$ will reduce the maximum deflection distance and the tether length and increase $\theta\left(h_{\text {gnd }}\right)$. This is favorable for improving the windresistant capabilities of the system, but it will increase the maximum tension in the tether and decrease $K_{S F}$, which is detrimental to the tether safety.

The effects of the aerodynamic parameters are shown in Table 4. The analysis results of the design optimization stage and the flight test stage show that the smaller the tether resistance coefficient $C_{n}$ is, the greater the advantage is both in $\max \left(K_{S F}\right)$ and the wind-resistant capabilities. The analysis of the design optimization design stage shows that the greater the balloon resistance coefficient $C_{b d}$ is, the greater $\max \left(K_{S F}\right)$ is. Furthermore, the lift coefficient $C_{b l}$ has very little effect on $\max \left(K_{S F}\right)$.
However, the analysis in the flight test stage shows that the greater is the balloon resistance coefficient $C_{b d}$ is, the greater $\max \left(K_{S F}\right)$ is. Furthermore, the lift coefficient $C_{b l}$ has little effect on $\max \left(K_{S F}\right)$. The analysis in the flight test stage shows that an increase in either $C_{b d}$ or $C_{b l}$ will cause the tether tension to increase and $K_{S F}$ to drop, and a drop in either $C_{b d}$ and $C_{b l}$ will cause the tether horizontal displacement to increase and the wind-resistant capabilities to degrade. It is necessary to consider this contradiction to ensure that the two parameters $C_{b d}$ and $C_{b l}$ vary within safe ranges.

\subsection{Feasibility analysis of long-duration flight}

The model parameters listed in Table 2 are based on models from the assumed maximum wind speed and average wind direction. We now analyze the feasibility of longduration flights using Model T1 in Table 2 and the 124 actual wind speeds and wind direction profiles in Fig. 3.

Table 4

Effects of aerodynamic parameters.

\begin{tabular}{|c|c|c|c|}
\hline Parameter & Tether resistance coefficient $C_{n}$ & Balloon resistance coefficient $C_{b d}$ & Aerodynamic lift coefficient $C_{b l}$ \\
\hline $\begin{array}{l}\text { Analysis in design } \\
\text { optimization stage }\end{array}$ & $\begin{array}{l}\text { The smaller } C_{n} \text { is, the greater } \max \\
\left(K_{S F}\right) \text { is }\end{array}$ & $\begin{array}{l}\text { The greater } C_{b d} \text { is, the greater max } \\
\left(K_{S F}\right) \text { is }\end{array}$ & $C_{b l}$ does not affect $\max \left(K_{S F}\right)$ \\
\hline $\begin{array}{l}\text { Analysis in flight test } \\
\text { stage }\end{array}$ & $\begin{array}{l}C_{n} \text { does not affect maximum tension of } \\
\text { tether; as } C_{n} \text { decreases, horizontal } \\
\text { displacement becomes smaller, and } \\
\text { wind-resistant capabilities increase. }\end{array}$ & $\begin{array}{l}\text { When } C_{b d} \text { increases, the maximum } \\
\text { tension of tether increases, and } K_{S F} \\
\text { decreases. When } C_{b d} \text { decreases, } \\
\text { horizontal displacement increases, and } \\
\text { wind-resistant capabilities decrease. }\end{array}$ & $\begin{array}{l}\text { As } C_{b l} \text { increases, the maximum tension } \\
\text { of tether increases, and } K_{S F} \text { decreases. } \\
\text { When } C_{b l} \text { decreases, horizontal } \\
\text { displacement increases, and wind- } \\
\text { resistant capabilities decrease. }\end{array}$ \\
\hline
\end{tabular}
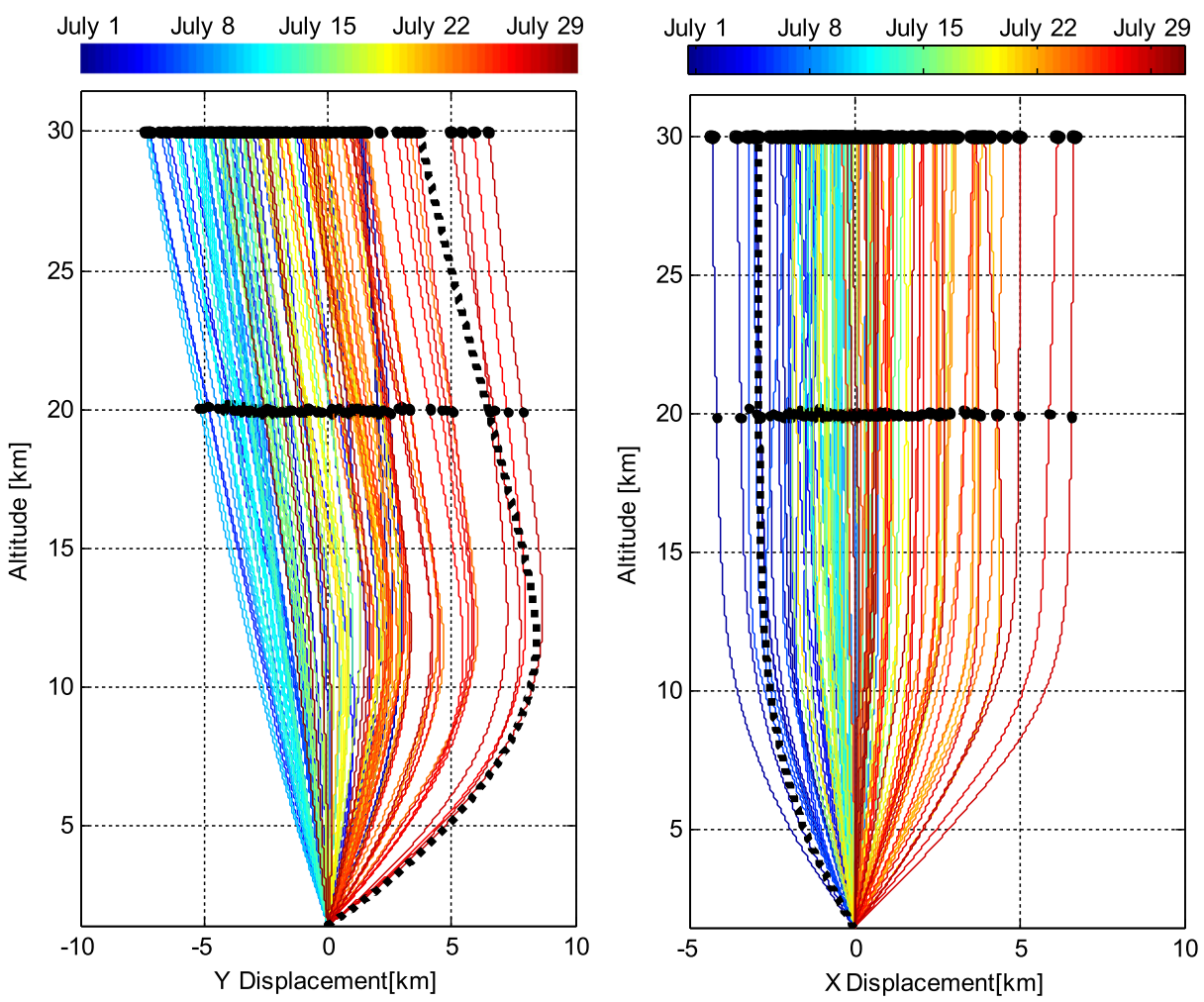

Fig. 29. Balloon and tether displacement after a one-month flight. 
The tether length during the flight was controlled in realtime using a winch system on the ground to maintain the top balloon at an operating altitude of $30 \mathrm{~km}$.

Fig. 29 shows the displacements of the balloon and the tether in the $\mathrm{Y}$ and $\mathrm{X}$ directions for the 124 actual wind fields in a month. The positive $\mathrm{Y}$ direction is the east, and the positive $\mathrm{X}$ direction is north. The colors of the displacement curves correspond to the colors of the wind field in Fig. 3. For the sake of comparison, the displacement for the maximum wind speed curve is also included in Fig. 29 as a black dashed line. The analysis results show that Model T1, designed based on the maximum wind speed, can adapt to various wind fields within a month, and the maximum positive displacement of the tether in the $\mathrm{Y}$ direction under the actual wind fields is smaller than the displacement designed based on the maximum wind speed. In the east and west directions, there is a switch of the wind direction, which can be used to reduce the tether displacement. Although there is no noticeable wind direction reversal in the south and north directions, the wind speeds in the south and north directions are statistically smaller, and the maximum $\mathrm{X}$ displacement in the actual wind fields is still slightly smaller than the maximum displacement in the $\mathrm{Y}$ direction.

Fig. 30 shows the maximum tether tension, tether length, and $\theta\left(h_{\text {gnd }}\right)$ of the tethered balloon system in the 124 actual wind fields over a month. It also shows the variation of the altitude of the middle balloon. The range of fluctuations for the maximum tension is $4870-5214 \mathrm{~kg}$, and the corresponding $K_{S F}$ range is $3.1-3.3$ and never decreases below the design value of 3 . There is a negative correlation between the total tether length and $\theta\left(h_{g n d}\right)$, so both parameters may be used as wind-resistant capability indicators for the system. The minimum value of $\theta\left(h_{\text {gnd }}\right)$ is $29.4^{\circ}$, which is slightly larger than the value of $28.7^{\circ}$ designed for the maximum wind speed. This shows that the wind-resistant capabilities of the system, designed for maximum wind speed, are adequate. The winch system on the ground only controls the operating altitude of the top balloon, and the altitude of the middle balloon changes accordingly, within a range of $19.84-20.2 \mathrm{~km}$, and remains relatively stable.

Based on the simulation analysis results for the wind field over a month, a comparison of part of the $\theta\left(h_{\text {gnd }}\right)$ data
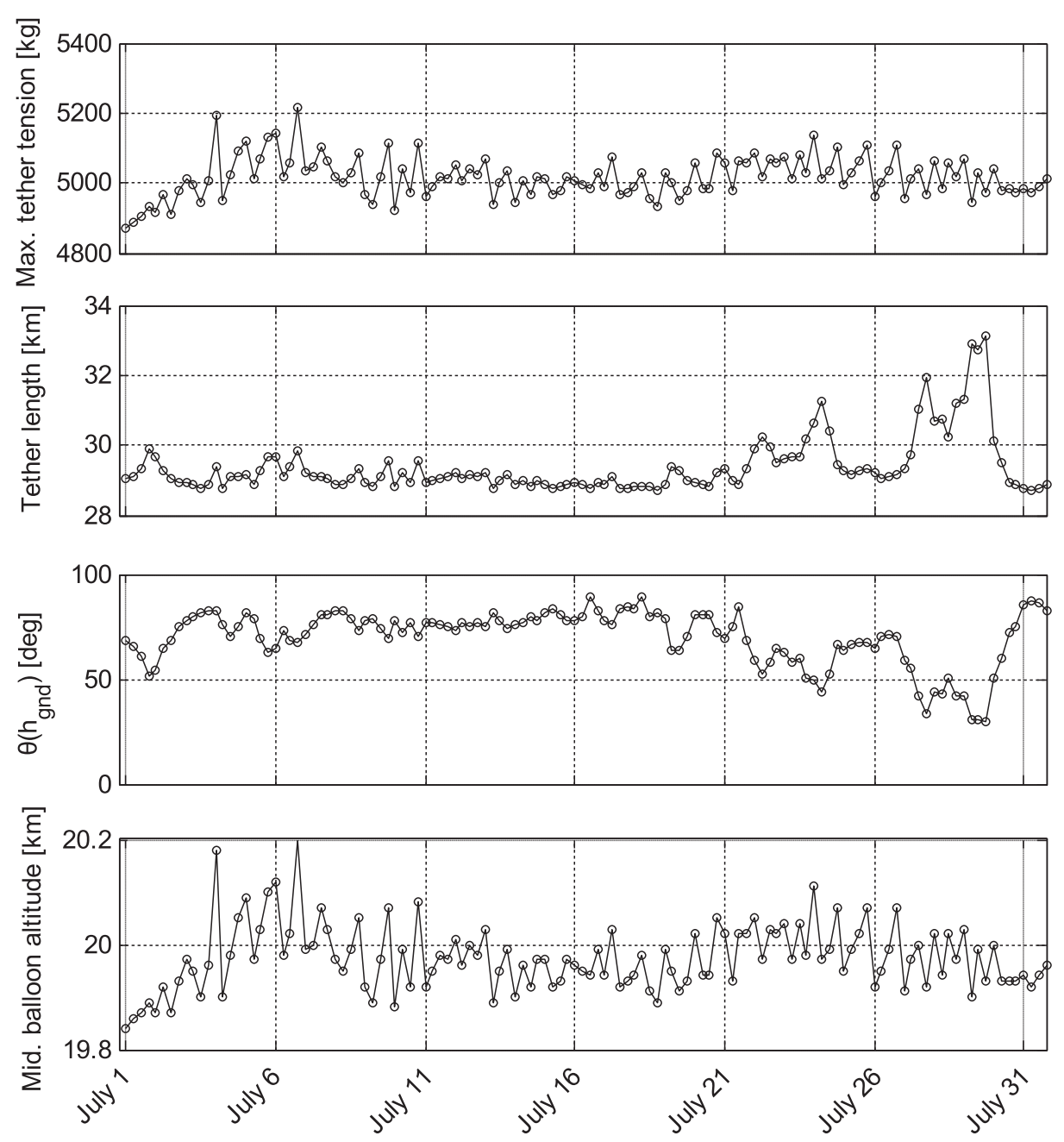

Fig. 30. Tether and balloon parameter variation of Model T1 balloon after a one-month flight. 


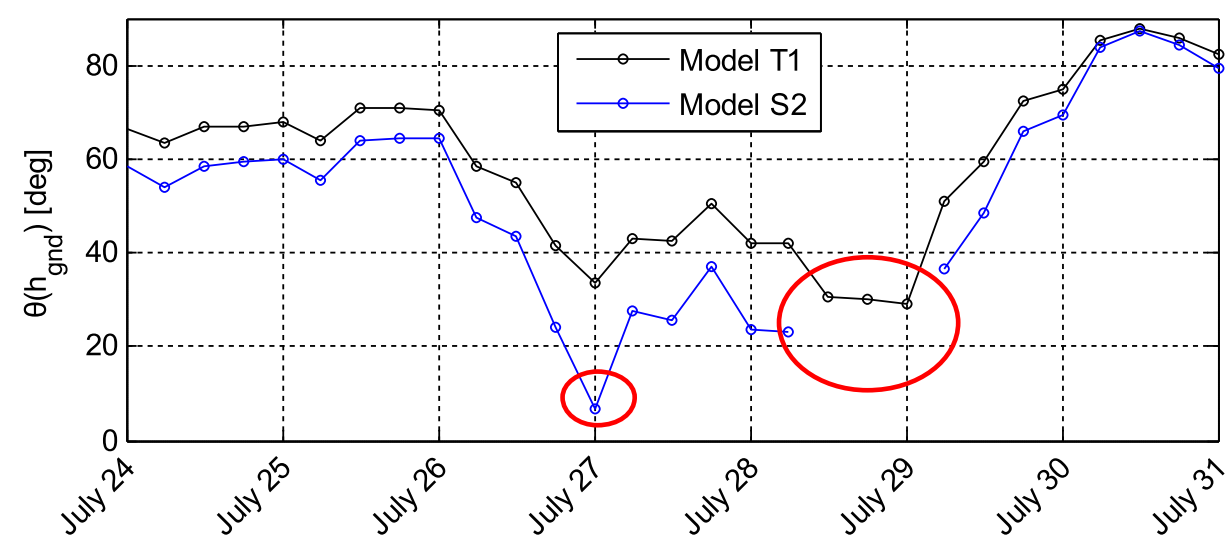

Fig. 31. Comparison of $\theta\left(h_{g n d}\right)$ during long-duration flight for Models T1 and S2.

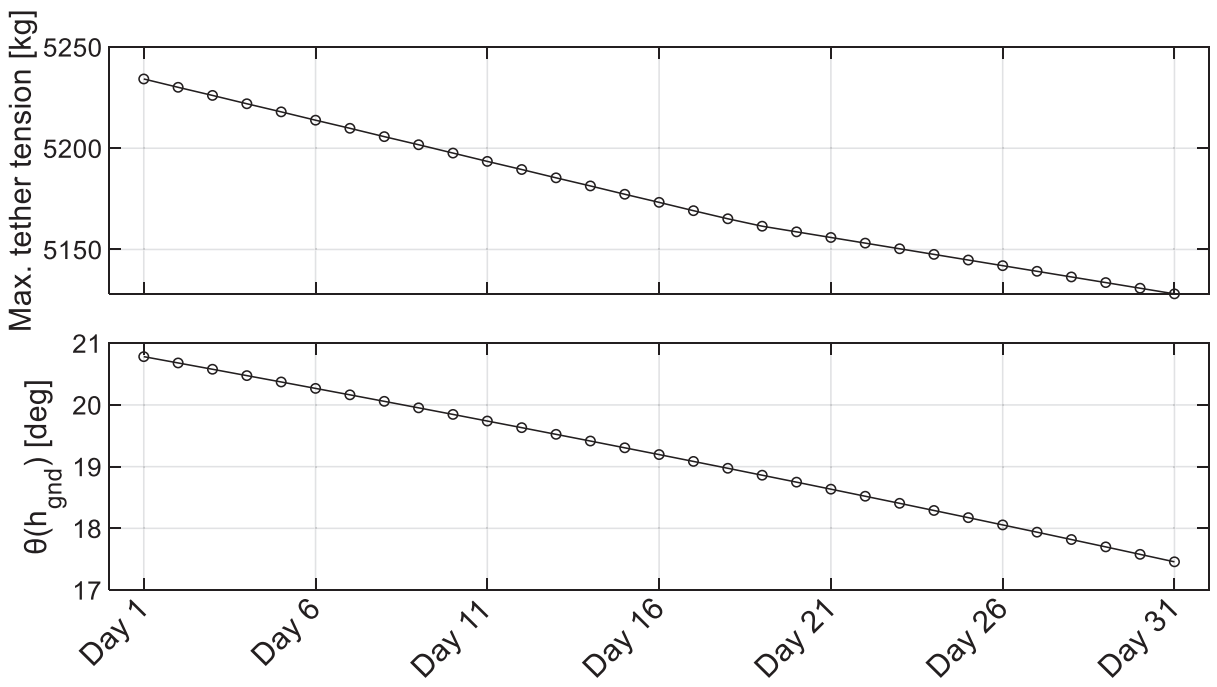

Fig. 32. Maximum tether tension and $\theta\left(h_{g n d}\right)$ variation during helium leakage.
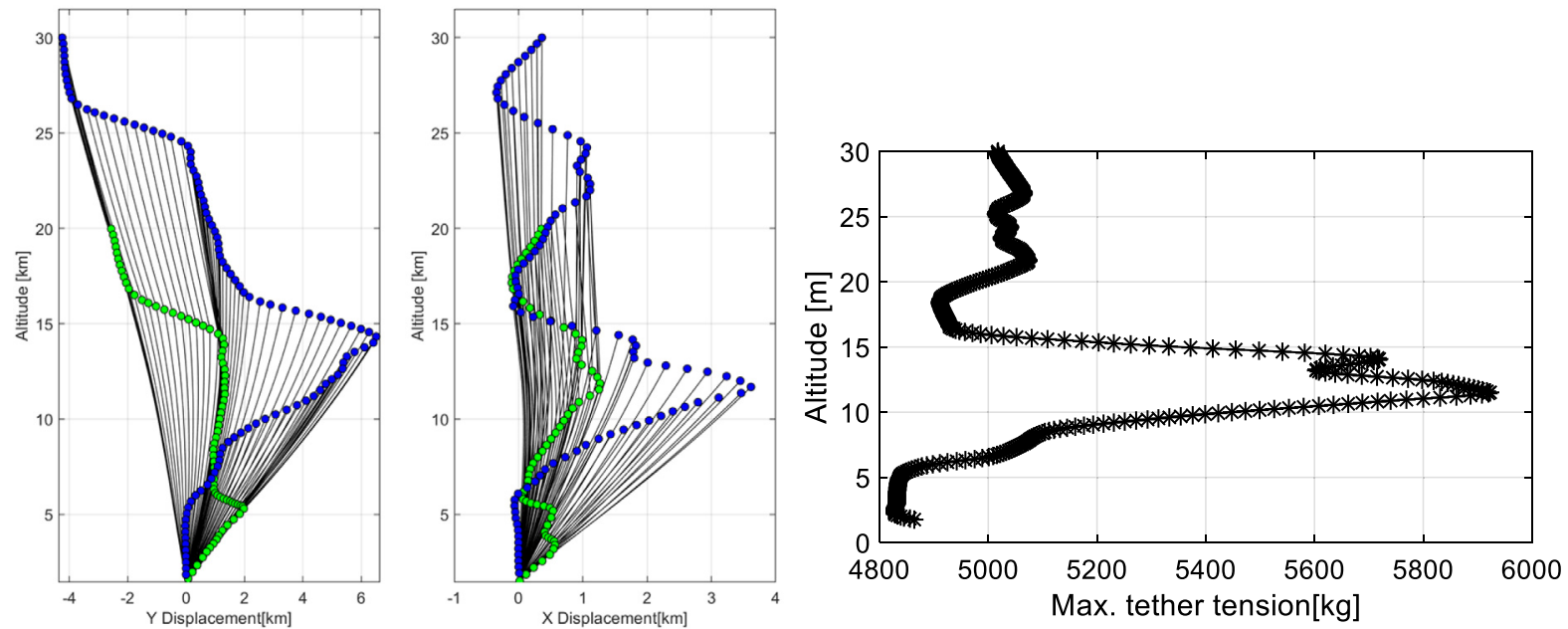

Fig. 33. Tether profile and changes of maximum tether tension during lift-off process at zero hours on 11 July. 


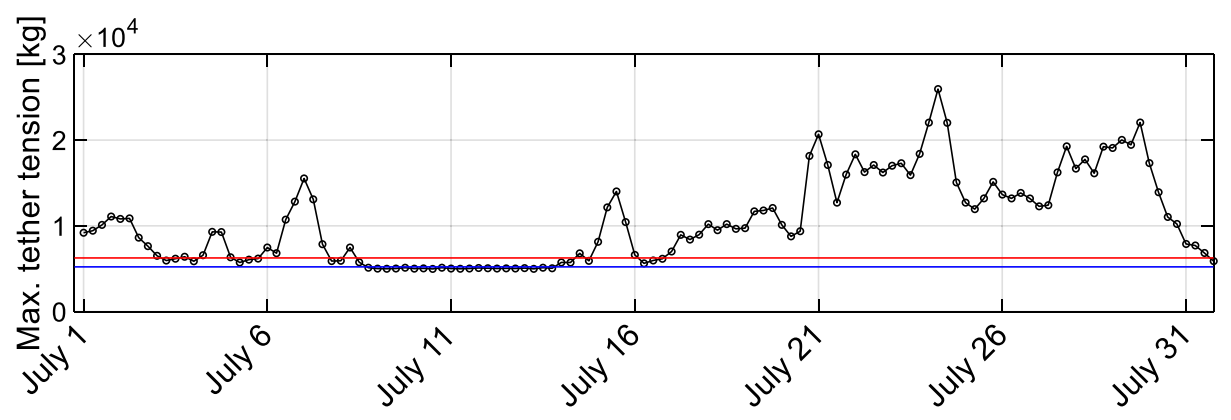

Fig. 34. Maximum tether tension at 124-time instances during lift-off.

of Models T1 and S2 is shown in Fig. 31. The results show that Model S2 has very small values of $\theta\left(h_{g n d}\right)$ at certain times and no $\theta\left(h_{\text {gnd }}\right)$ at other times because it cannot resist the wind speed at those times. At all times, Model T1 has a greater $\theta\left(h_{g n d}\right)$ than Model S2, indicating that it has better wind-resistant capabilities.

For the integrated balloon membrane material and manufacturing technology, the helium gas leakage analysis was based on a leakage rate of $5 \mathrm{~L} / \mathrm{m}^{2} /$ day. Thus, for the top balloon of model T1, the leakage of helium was $0.459 \mathrm{~kg} / \mathrm{day}$, and the loss helium of middle balloon was $0.046 \mathrm{~kg} /$ day. After $31 \mathrm{~d}$ under the condition of maximum wind speed, the maximum tether tension decreased by $106.1 \mathrm{~kg}$, and $\theta\left(h_{\text {gnd }}\right)$ decreased by $3.3^{\circ}$. This indicates that helium leakage had little effect on the 31-d flight (see Fig. 32).

As launch is an important problem of the tethered balloon system. We conducted simulation analysis of the lift-off process for all the wind profile curves shown in Fig. 3. Fig. 33 shows the tether profile and changes of maximum tether tension during the lift-off process at one of the 124-time instances. Fig. 34 shows maximum tether tension at 124-time instances during lift-off. In terms of tether safety, 21 of the wind field conditions (or 16.9\%) are safe for launch, another 16 wind field conditions exceeded the design tension of the tether but by less than $20 \%$, while the remaining wind field conditions are very dangerous. The results indicate that chosen of the meteorological windows for launch is very important.

\section{Conclusion}

In this paper, a tandem ultra-high-altitude tethered balloon model and a design method based on the principle of constant $K_{S F}$ were proposed. The tandem tethered balloon only requires the addition of a middle balloon with a very small volume compared to that of the top balloon in tandem in the weak wind zone. Such an addition can greatly extend the operating altitude of the tethered balloon and, by exploiting the wind field characteristics of opposite wind directions at high and low altitudes, reduce the horizontal displacement of the tether and improve the tether safety factor and the wind-resistant capabilities.
In this paper, we established a three-dimensional static model for a tandem ultra-high-altitude tethered balloon and conducted a comparative analysis for tandem and single balloon models. We also conducted a systematic sensitivity analysis of parameters such as the tether diameter, tether resistance coefficient, balloon resistance coefficient, and aerodynamic lift coefficient and performed a feasibility study of long-duration flights. The following conclusions were drawn:

- Increasing the diameter of the tether and decreasing $C_{n}$ can both significantly increase $\max \left(K_{S F}\right)$, but increasing the diameter of the tether will increase the balloon volume and the system cost. Decreasing $C_{n}$ does not change the balloon volume and should be given preferred consideration.

- Parameter sensitivity analyses conducted in the design optimization stage and the flight test stage have different importance for the system design and implementation. For example, analysis in the design optimization stage showed that increasing $C_{b d}$ can increase $\max \left(K_{S F}\right)$, and variations of $C_{b l}$ do not affect $\max \left(K_{S}\right)$. However, analysis at the flight test stage showed that both $C_{b d}$ and $C_{b l}$ should be kept at the design values or varied within a small interval, because an increase of $C_{b d}$ and $C_{b l}$ will reduce $K_{S F}$, and a decrease will reduce the windresistant capabilities. Both would adversely affect the system.

- Simulation analysis results of a tandem tethered balloon model designed for an assumed maximum wind speed during a month-long actual wind field test showed that the maximum tension of the tether and $\theta\left(h_{g n d}\right)$ were both within the design ranges, confirming that the model is viable for complex and variable wind field environments and capable of long-duration flights.

The results of this paper are based on the static simulation analysis of the stable dwelling characteristics of the tandem stratosphere tethered balloon. The dynamic characteristics of tandem stratosphere tethered balloons have yet to be investigated. This article only presents a design principle for the overall parameters. The stratospheric tethered balloon system is a complex engineering system that 
faces many practical problems, such as pressure control, altitude control, launching, and recovery. These problems await further studies.

\section{Declaration of Competing Interest}

The authors declare that they have no known competing financial interests or personal relationships that could have appeared to influence the work reported in this paper.

\section{Acknowledgments}

This work was supported by the Strategic Priority Research Program of the Chinese Academy of Science (Grant No. XDA17020501) and the Innovation Program of Academy of Opto-Electronics of the Chinese Academy of Science (Grant No. Y50B07A16Y).

\section{References}

Akita, D., 2012. Feasibility study of a sea-anchored stratospheric balloon for long-duration flights. Adv. Space Res. 50 (4), 508-515.

Badesha, S., Bunn, J., 2002. Dynamic simulation of high altitude tethered balloon system subject to thunderstorm windfield. In: AIAA Atmospheric Flight Mechanics Conference and Exhibit, p. 4614.

Badesha, S., Euler, A., Schroder, L., 1996. Very high altitude tethered balloon parametric sensitivity study. 34th Aerospace Sciences Meeting and Exhibit AIAA, 0579.

Belmont, A.D., Dartt, D.G., Nastrom, G.D., 1975. Variations of stratospheric zonal winds, 20-65 km, 1961-1971. J. of Appl. Meterol. 14 (4), 585-594.

Bents, D.J., 2011. Long-duration low-to medium-altitude solar electric airship concept. NASA/TM-2011-216815, E-17446.

Carroll, J.A., 1985. Guidebook for analysis of tether applications. Final Report on Contract RH4-394049.

Cathey, H.M., 2008. Development overview of the revised NASA Ultra Long Duration Balloon. Adv. Space Res. 42 (10), 1624-1632.

Cathey, H.M., Fairbrother, D.A., Said, M.A., 2017. Performance highlights of NASA super pressure balloon mid-latitude flights. In: AIAA Balloon Systems Conference, p. 3091.

Chiba, K., Nishikawa, R., Onda, M., et al., 2017. Aerodynamic influences on a tethered high-altitude lighter-than-air platform system to its behavior. Aerosp. Sci. Technol. 70, 405-411.

Chiba, K., Satori, S., Hiramoto, R., et al., 2015. Feasibility studies on a high-altitude captive lighter-than-air platform system. 15th AIAA Aviation Technology, Integration, and Operations Conference.
Costello, H., Kuo, K., Hunt, H., 2012. Stability analysis of an aerodynamically shaped high-altitude-balloon tether. In: International Conference on Noise \& Vibration Engineering, pp. 3003-3012.

Davidson, P., Burgoyne, C., Hunt, H., et al., 2012. Lifting options for stratospheric aerosol geoengineering: advantages of tethered balloon systems. Philos. Trans. Royal Soc. A: Mathem., Phys. Eng. Sci. 1974 (370), 4263-4300.

Doliveira, F.A., De Melo, F.C., Devezas, T.C., et al., 2016. High-altitude platforms - present situation and technology trends. J. Aerosp. Technol. Manage. 8 (3), 249-262.

Euler, A., Badesha, S., Schroeder, L., 1995: 1612.. Very high altitude tethered balloon feasibility study. In: 11th AIAA Lighter-than-Air Systems Technology Conference, p. 1612.

Gonzalo, J., López, D., Domínguez, D., et al., 2018. On the capabilities and limitations of high altitude pseudo-satellites. Prog. Aerosp. Sci. 98, $37-56$.

Grant, D., Rand, J., 1996. Dynamic analysis of an ascending high altitude tethered balloon. 34th Aerospace Sciences Meeting and Exhibit AIAA, 578.

Hwang, S.J., Kim, S.G., Kim, C.W., Lee, Y.G., 2016. Aerodynamic design of the solar powered high altitude long endurance (HALE) unmanned aerial vehicle (UAV). Int. J. Aeronaut. Space Sci. 17 (1), 132-138.

Izetunsalan, K., Unsalan, D., 2011. A low cost alternative for satellitestethered ultra-high altitude balloons. In: International Conference on Recent Advances in Space Technologies, pp. 13-16.

Jones, S.P., Schroder, L.D., 2001. Nonlinear dynamic simulation of a tethered aerostat: a fidelity study. J. Aircraft 38 (1), 64-68.

Kubara, R.S., 1974. The national scientific balloon facility. https://ntrs. nasa.gov/search.jsp?R=19750004679 2018-05-16T14:14:26+00:00Z.

Menke, J.A., 1967. High-altitude tethered balloon systems study. Task report No 1, Goodyear Aerospace Corporation, May 1967.

Miller, S.H., Fesen, R., Hillenbrand, L., et al., February 2014. Airships: a new horizon for science. Physics 1.

Saito, Y., Iijima, I., Matsuzaka, Y., Matsushima, K., et al., 2014. Development of a super-pressure balloon with a diamond-shaped net. Adv. Space Res. 54 (8), 1525-1529.

St, U.S., 1976. Atmosphere. U.S. Government Printing Office, Washington, D.C.

Wilcox, B.H., Schneider, E.G., Vaughan, D.A., Hall, J.L., Yu. C.Y., 2011. Low-cost propellant launch to LEO from a tethered balloon'Propulsion depots' not 'propellant depots'." Aerospace Conference 2011 IEEE, 1-14.

Xu, Y., Zhu, W., Li, J., Zhang, Z., 2020. Improvement of endurance performance for high-altitude solar-powered airships: a review. Acta Astronaut. 167, 245-259.

Yoder, C.D., Gemmer, T.R., Mazzoleni, A.P., 2019. Modelling and performance analysis of a tether and sail-based trajectory control system for extra-terrestrial scientific balloon missions. Acta Astronaut. 160, 527-537.

Zhu, X., Guo, Z., Hou, Z., 2014. Solar-powered airplanes: a historical perspective and future challenges. Prog. Aerosp. Sci. 71, 36-53. 